\title{
Moisture Attribution and Sensitivity Analysis of a Winter Tornado Outbreak
}

\author{
MARIA J. MOLINA ${ }^{\mathrm{a}}$ \\ National Center for Atmospheric Research, Boulder, Colorado, and Department of Earth and Atmospheric Sciences, \\ Central Michigan University, Mount Pleasant, Michigan
}

JOHN T. ALLEN

Department of Earth and Atmospheric Sciences, Central Michigan University, Mount Pleasant, Michigan

ANDREAS F. PREIN

National Center for Atmospheric Research, Boulder, Colorado

(Manuscript received 4 December 2019, in final form 7 May 2020)

\begin{abstract}
The tornado outbreak of 21-23 January 2017 caused 20 fatalities, more than 200 injuries, and over a billion dollars in damage in the Southeast United States. The event occurred concurrently with a record-breaking warm Gulf of Mexico (GoM) basin. This article explores the influence that warm GoM sea surface temperatures (SSTs) had on the tornado outbreak. Backward trajectory analysis, combined with a Lagrangianbased moisture-attribution algorithm, reveals that the tornado outbreak's moisture predominantly originated from the southeast GoM and the northwest Caribbean Sea. We used the WRF Model to generate a control simulation of the event and explore the response to perturbed SSTs. With the aid of a tornadic storm proxy derived from updraft helicity, we show that the 21-23 January 2017 tornado outbreak exhibits sensitivity to upstream SSTs during the first day of the event. Warmer SSTs across remote moisture sources and adjacent waters increase tornado frequency, in contrast to cooler SSTs, which reduce tornado activity. Upstream SST sensitivity is reduced once convection is ongoing and modifying local moisture and instability availability. Our results highlight the importance of air-sea interactions before airmass advection toward the continental United States. The complex and nonlinear nature of the relationship between upstream SSTs and local precursor environments is also discussed.
\end{abstract}

\section{Introduction}

The 21-23 January 2017 tornado outbreak was a destructive meteorological event for the Southeast United States. Despite the low climatological likelihood of tornado occurrence during January (e.g., Brooks et al. 2003), winter tornadoes have a proclivity to impact highdensity population areas across the Southeast, propensity for nocturnal initiation, and reduced societal awareness (e.g., Ashley et al. 2008; Kis and Straka 2010; Ashley and Strader 2016; Krocak and Brooks 2018). The 21-23 January 2017 tornado outbreak resulted in 83 tornadoes, 204 injuries, 20 fatalities, and over

\footnotetext{
${ }^{a}$ Current affiliation: National Center for Atmospheric Research, Boulder, Colorado.
}

Corresponding author: Maria J. Molina, molina@ucar.edu
$\$ 1$ billion (U.S. dollars) in losses (Smith and Matthews 2015). January 2017 was also the warmest month on record for surface waters of the Gulf of Mexico (GoM) basin (1982-2019; Reynolds et al. 2007), which are a primary source of boundary layer moisture for winter tornadic convection (e.g., Lewis and Crisp 1992; Jung and Kirtman 2016; Molina et al. 2016, 2018). We hypothesize that the significance and extent of the event was at least partly attributable to the anomalous warmth of GoM sea surface temperatures (SSTs). This research study aims to examine this hypothesis.

The science of attributing specific causes to extreme weather events has made strides in recent years, with an emphasis on attribution to global warming (e.g., Trenberth et al. 2015; Herring et al. 2018). Past studies have incorporated the use of model simulations with perturbed variables to assess changes to meteorological events (e.g., Stott et al. 2016; Hoerling and Quan 2016; 
Prein et al. 2017b). While the emphasis herein does not lie in climate change attribution, this research is partly motivated by the potential implications of a GoM that has been warming over the last several decades (e.g., Diffenbaugh et al. 2008; Brooks 2013; Allard et al. 2016; Allen 2018). However, more central to this work is advancing the fundamental understanding of environments that can lead to tornado development during winter months (e.g., Sherburn and Parker 2014; King et al. 2017). Of particular interest is the influence that the temperature of a moisture source has on downstream thermodynamic buoyancy and convection (Edwards and Weiss 1996; Lanicci and Warner 1997; Evans and Guyer 2006; Guyer et al. 2006). This relationship can be evaluated by exploring the sensitivity of the 21-23 January 2017 tornado outbreak to temperatures of nearby moisture sources using a series of model simulations.

Uncertainty regarding the extent of air mass modification over the GoM led to the creation of a field campaign in the 1980s called the Gulf of Mexico Experiment (GUFMEX; Lewis et al. 1989). The study was motivated by difficulties in forecasting convective events over the CONUS during late winter and early spring, when polar air masses can be advected over the GoM and return with highly variable moisture content and thermodynamic buoyancy (Lewis et al. 1989). A series of observational and modeling studies resulted from the field project, which demonstrated that GoM surface fluxes can heat and moisten boundary layer air masses that can be subsequently advected toward the CONUS (e.g., Weiss 1992; Lewis and Crisp 1992; Janish and Lyons 1992; Mailhot 1992; Burk and Thompson 1992; Thompson and Burk 1993). However, GUFMEX was limited to 20 February-2 April 1988, constraining the sample size of observations and broader conclusions that could be inferred from the data. Understanding the influence of GoM SSTs on overlying air masses and resultant convection activity remains an active area of research (e.g., Lewis et al. 2016; Lakshmivarahan et al. 2017).

Winter thunderstorm development is generally preceded by the transport of water vapor that spans a synoptic-scale distance (e.g., $\geq 1000 \mathrm{~km}$; Barnes and Newton 1986; Lewis et al. 1989; Weiss 1992; Doswell and Bosart 2001; Molina and Allen 2019, 2020). Boundary layer moisture for winter convective events can be advected northward by extratropical cyclones, which are generated in response to synoptic-scale troughing within the jet stream (e.g., Doswell and Bosart 2001). The jet stream and extratropical cyclones contribute to a background state consisting of favorable kinematics for severe convection (defined as thunderstorms producing tornadoes, large hail, and/or damaging winds) during winter months (Guyer et al. 2006; Sherburn and Parker
2014; Cook et al. 2017; King et al. 2017; Childs et al. 2018; Molina et al. 2018). Relatively small increments of low-level buoyancy can provide sufficient instability for the development of winter convection and can be a discriminating factor between a severe and a nonsevere thunderstorm (King et al. 2017). These severe thunderstorm environments are referred to as "high-shear low-CAPE" (convective available potential energy) environments (Sherburn and Parker 2014) and continue to pose a challenge to operational forecasters given the high rate of false alarms (Vescio and Thompson 1998). Upstream surface water temperatures can modulate the water vapor content of air within the boundary layer and thermodynamic buoyancy, and therefore a tornado event's degree of sensitivity to these temperatures is important to explore.

This paper is structured as follows. A synopsis of the synoptic and mesoscale details of the tornado outbreak is provided before addressing the two main objectives of this study. The first goal is to quantify the origins of moisture that contributed to the 21-23 January 2017 tornadic storms to determine the extent of GoM influence. The second aim is to explore the sensitivity of the tornado outbreak to surface water temperatures of the respective source regions, by perturbing upstream SSTs. Results from this research have several broader forecasting and climate implications that will be discussed to conclude the article.

\section{Data and methods}

\section{a. Data for synoptic and mesoscale overview}

To analyze the environment of the 21-23 January 2017 tornado outbreak, meteorological variables were sourced from the 3-hourly and 32-km horizontal grid spacing North American Regional Reanalysis (NARR; Mesinger et al. 2006). NARR was used because its temporal resolution and horizontal grid spacing can capture subdaily along-trajectory changes, and its geographic domain extends beyond the CONUS and GoM basin. NARR also has skillful representation of kinematic fields, which are beneficial during the modeling of backward trajectories and during the mesoscale analysis of wind shear for the 21-23 January tornado outbreak. NARR does suffer from limitations related to the accurate depiction of low-level moisture fields (at times a dry bias; Gensini et al. 2014), which will be important to consider in subsequent moisture attribution and sensitivity analyses. However, Gensini et al. (2014) focused on NARR environments of the central and eastern CONUS, primarily away from the Gulf Coast, and it is therefore difficult to know whether the Gulf Coast is similarly affected. Radar reflectivity data were also 
acquired to describe the event's convective morphology. Gridded radar reflectivity was sourced from GridRad (Bowman and Homeyer 2017), which consists of a composite of multiple radars, compiled using a weighted average (Homeyer and Bowman 2017) of NOAA Weather Surveillance Radar-1988 Doppler network Level II data (courtesy of C. R. Homeyer 2019, personal communication). GridRad has a grid spacing of $0.02^{\circ}$ in the horizontal and $1 \mathrm{~km}$ in the vertical, at hourly temporal resolution. It was also of interest to compare the event's upstream SSTs to climatological history (1982-2019). SSTs were sourced from the $0.25^{\circ}$, daily resolution NOAA National Centers for Environmental Information optimum interpolation SSTs (Reynolds et al. 2007). This SST product uses Advanced Very High Resolution Radiometer (AVHRR) infrared satellite SST data (May et al. 1998). Areaaveraged SSTs were computed for the GoM basin $\left(18.5^{\circ}-30.5^{\circ} \mathrm{N}, 98^{\circ}-82^{\circ} \mathrm{W}\right)$ and daily SST anomalies (SSTAs) were calculated using a weekly climatology.

The Storm Prediction Center (SPC) maintains a database of contiguous United States (CONUS) tornado reports (Schaefer and Edwards 1999) that includes the estimated time and location of tornado occurrence, associated fatalities, injuries, and intensity rating based on damage indicators (Fujita 1971; Potter 2007; Edwards et al. 2013). Tornado information for 21-23 January 2017 was accessed from this SPC dataset. The hourly, threedimensional SPC mesoanalysis system (Bothwell et al. 2002) was also used to analyze meteorological fields of the 21-23 January 2017 tornado outbreak. The Mesoanalysis system incorporates an objective analysis of surface observations that is blended with the hourly, operational National Centers for Environmental Prediction (NCEP) Rapid Refresh (RAP; Benjamin et al. 2016). During this process, the NSHARP Sounding Analysis program (Hart and Korotky 1991; Blumberg et al. 2017) is applied to data at each grid point in order to output more than a hundred variables and parameters that characterize environments of severe thunderstorms. These parameters include mixedlayer convective available potential energy (MLCAPE; $\mathrm{J} \mathrm{kg}^{-1}$ ), which represents the lifting of a mean thermodynamic parcel from the lowest 100 -hPa pressure levels, and $0-6-\mathrm{km}$ bulk vertical wind shear $\left(\mathrm{kt} ; 1 \mathrm{kt} \approx 0.51 \mathrm{~m} \mathrm{~s}^{-1}\right)$.

\section{b. Moisture attribution: HYSPLIT model}

The NOAA/Air Resources Laboratory (ARL) Hybrid Single-Particle Lagrangian Integrated Trajectory model (HYSPLIT) was used to compute backward trajectories to determine the origins of air masses (Draxler and Hess 1997; Stein et al. 2015). Trajectories were used to identify the moisture source regions of the 21-23 January 2017 tornado outbreak. Air parcel trajectories were initialized from the start coordinates of tornado paths for 2123 January 2017 contained in the SPC tornado report dataset (Schaefer and Edwards 1999), using NARR in ARL format. NARR was used to ensure comparability to Molina and Allen (2019), which created a climatology of the moisture sources of tornadic convection using NARR. HYSPLIT computes trajectories using linear interpolation of meteorological variables calculated at 0.75 of every NARR grid cell (recommended setting; Draxler and Hess 1997) intersected by the respective trajectory. Tests were run using higher spatial resolution calculations (e.g., 0.25) and were found to produce similar results to the default HYSPLIT setting. Trajectory data were output on an hourly basis. Choosing a total trajectory runtime can be somewhat arbitrary, but in this case, trajectories were allowed to run for $168 \mathrm{~h}$ ( 7 days) back in time because moisture has a residence time of at least 4-5 days (Läderach and Sodemann 2016) and possibly as many as 8 days (Trenberth 1998). When backward trajectories exited the NARR geographical domain before $168 \mathrm{~h}$, they were concluded at that time.

Rather than generating one trajectory per tornado report and analogous to previous studies (e.g., Gustafsson et al. 2010; Erlingis et al. 2019; Molina and Allen 2019), a three-dimensional matrix consisting of $11 \times 11 \times 11$ points (1331 total) was released (per tornado report) and centered at the height of the planetary boundary layer (HPBL). This matrix method was done to account for some uncertainty in air mass dispersion from turbulent fluxes and trajectory sensitivity to the gridded nature of reanalysis data (Stohl 1998). Every matrix layer was composed of 121 trajectories spaced on a $16-\mathrm{km}$ horizontal grid with a vertical spacing of one-tenth fraction of the HPBL. As described in Schmid and Niyogi (2012), the HPBL obtained from the NARR dataset was previously derived using equilibrium turbulent kinetic energy (Janjić 1996), which is comparable in skill to other modelderived HPBL (Angevine and Mitchell 2001).

PySPLIT (Warner 2018) is a Python-based library for HYSPLIT that was used to conduct various along-trajectory calculations, including moisture flux $\left(\mathrm{m} \mathrm{s}^{-1} \mathrm{~g} \mathrm{~kg}^{-1}\right)$ and moisture uptake (MU; Sodemann et al. 2008). Moisture flux was computed in PySPLIT as the product of the horizontal velocity vector $\mathbf{V}\left(\mathrm{m} \mathrm{s}^{-1}\right)$ and specific humidity $q$ $\left(\mathrm{g} \mathrm{kg}^{-1}\right)$, providing insight into the meridional and zonal advection of moisture. The MU algorithm was developed by Sodemann et al. (2008) and is based on mass conservation principles, where moisture increases and decreases $(\Delta q)$ are assumed to be from evaporation and precipitation, respectively. The MU algorithm was used to demarcate surface areas where air parcels acquired moisture that contributed to the tornado outbreak by tracking alongtrajectory $\Delta q$. The $\Delta q$ is the change in specific humidity at 
the start and end points of the respective 6-h interval along the trajectory, a time period of sufficient length for evaporation or precipitation to occur (Sodemann et al. 2008). As in prior studies that employed this diagnostic (e.g., Baldini et al. 2010; Pfahl et al. 2014), an interval was marked as an MU if $\Delta q$ was $\geq+0.2 \mathrm{~g} \mathrm{~kg}^{-1}$ during a $6-\mathrm{h}$ interval at a height $\leq$ HPBL, which we used to delimit surface sources (e.g., ocean) from elevated sources (e.g., evaporating hydrometeors). The sensitivity of MU to the HPBL vertical threshold was tested by also running the MU calculation using 900 and $300 \mathrm{hPa}$ as vertical delimiters and differences were found to be negligible. The levels 900 and $300 \mathrm{hPa}$ were used for the sensitivity tests to explore whether substantial moisture contributions originated from the free atmosphere as opposed to surficial sources. Increases in $\Delta q$ that are less than $+0.2 \mathrm{~g} \mathrm{~kg}^{-1}$ are not considered since they are insignificant from a thermodynamic perspective (Sodemann et al. 2008; Pfahl et al. 2014).

Weights were assigned to each MU that reflected the 6-h interval's final contribution extent along the trajectory by using fractional contributions:

$$
f=\frac{\Delta q}{q} .
$$

Fractional contributions were recursively updated as new MU occurred while the calculation proceeded forward in time,

$$
f_{m-6 \mathrm{~h}}=\frac{\Delta q_{m-6 \mathrm{~h}}}{q_{m}},
$$

where $m$ represents the current 6 -h time interval and $m-$ $6 \mathrm{~h}$ represents the past 6-h time interval. Along-trajectory precipitation was denoted when $\Delta q \leq-0.2 \mathrm{~g} \mathrm{~kg}^{-1}$, in which case previous MUs along the respective trajectory were revised as follows:

$$
\Delta q_{m-6 \mathrm{~h}}^{\prime}=\Delta q_{m-6 \mathrm{~h}}+\left(\Delta q_{m} \times f_{m-6 \mathrm{~h}}\right) .
$$

As in Sodemann et al. (2008, and others), trajectories were filtered before computing MU. Backward trajectories initialized from grid points with relative humidity $\geq 65 \%$ were considered for the MU calculation, given the association of the threshold with tornadic supercells (Thompson et al. 2003). 95\% of all trajectories satisfied the relative humidity criteria. As in Molina and Allen (2019), all trajectory data were binned onto $80 \mathrm{~km} \times$ $80 \mathrm{~km}$ grids and MU was weighted by daily trajectory intersections at each grid cell.

\section{c. Moisture sensitivity: WRF Model}

Past studies have dynamically downscaled reanalysis datasets to convection-allowing resolutions for retrospective representation of thunderstorms (e.g., Trapp et al. 2011; Robinson et al. 2013; Gensini and Mote 2014; Liu et al. 2017; Trapp and Hoogewind 2016; Hoogewind et al. 2017). Nonhydrostatic model simulations with 4-km horizontal grid spacing have been shown in some cases to add value to predictions of mesoscale evolution and morphology, particularly when compared to coarser grid spacing model simulations that use convection parameterizations (e.g., Done et al. 2004; Kain et al. 2006; Weisman et al. 2008; Prein et al. 2015, 2017a). Thus, following moisture attribution, the nonhydrostatic Advanced Research core of the Weather Research and Forecasting model (WRF) version 4.0 (Skamarock and Klemp 2008) was used to create simulations of the 21-23 January 2017 tornado outbreak. WRF was run at convection-allowing horizontal grid spacing $(4 \mathrm{~km})$ within a domain that encompassed the location of the tornado outbreak and marine areas that were found to be sources of moisture (e.g., GoM and the Caribbean Sea; Fig. 1). NARR was used as the initial and lateral boundary conditions for consistency with previously generated HYSPLIT trajectories. Numerical details of the WRF simulation setup can be found in Table 1 . The simulation was run continuously (without restarts) for 8 days (from 0900 UTC 15 January to 0900 UTC 23 January) to allow SST perturbations to sufficiently precondition the downstream environment during the days preceding the event. The continuous integration was done for all WRF simulations. Since the choice of microphysics parameterizations can influence the evolution of modeled convection due to the emulation of processes that affect hydrometeor distributions, we created a six-member ensemble of the tornado outbreak using various schemes (Table 2) that have been used in previous convection-allowing modeling studies (Liu et al. 2017; Hoogewind et al. 2017). The nonlocal Yonsei University (YSU) scheme (Hong et al. 2006) has been found to more accurately represent entrainment processes and deeper vertical mixing within the planetary boundary layer (Cohen et al. 2015, 2017) and was thus used in all simulations. While a grid spacing of $4 \mathrm{~km}$ can be sufficient to allow deep convection (Bryan et al. 2003), subgrid cloud cover is not captured. However, in this case, testing showed little change when using subgrid cloud cover parameterization and it was therefore not used (akin to earlier studies; Liu et al. 2017).

Initial testing revealed that the dynamically downscaled WRF solution diverged from reanalysis input due in part to the simulation's extended runtime and large spatial domain. Thus, spectral nudging (e.g., von Storch et al. 2000) of air temperatures, horizontal winds, and geopotential heights above the HPBL was applied using a moderate strength nudging coefficient (Table 1). This nudging was done to allow the unconstrained evolution 
a) Case Study Domain

b) 0900-2100 UTC 21 January

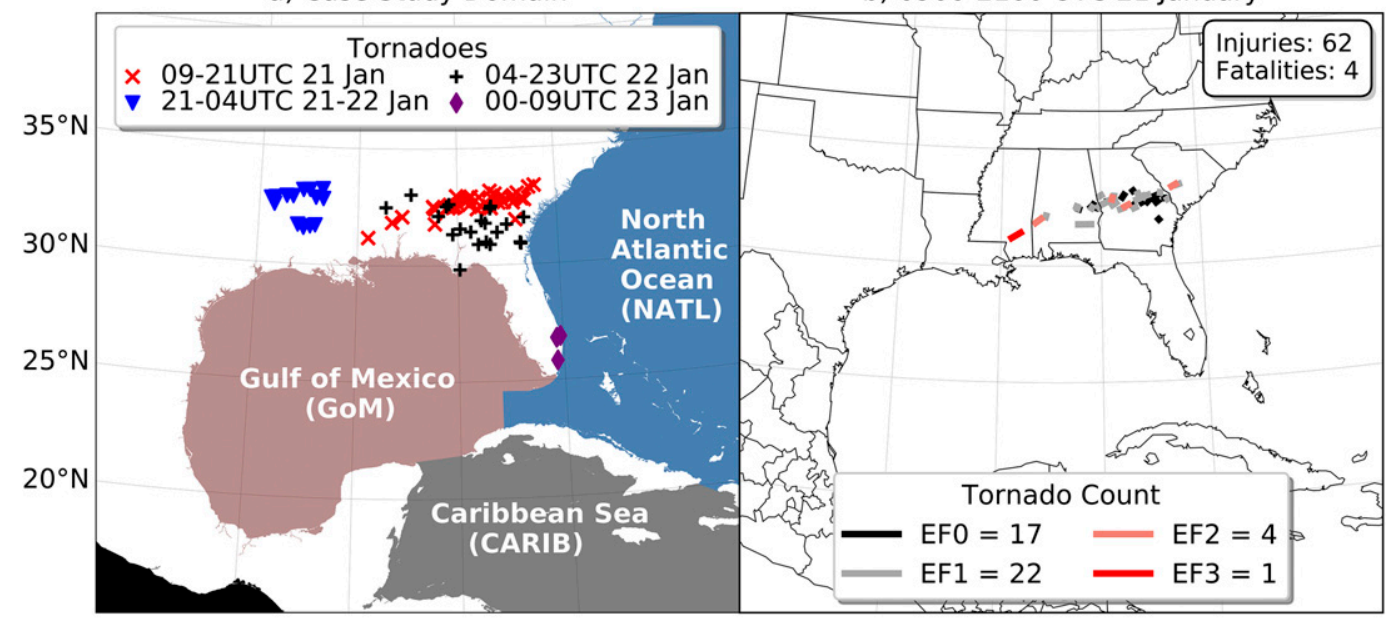

c) 2100-0400 UTC 21-22 January

d) 0400-2300 UTC 22 January

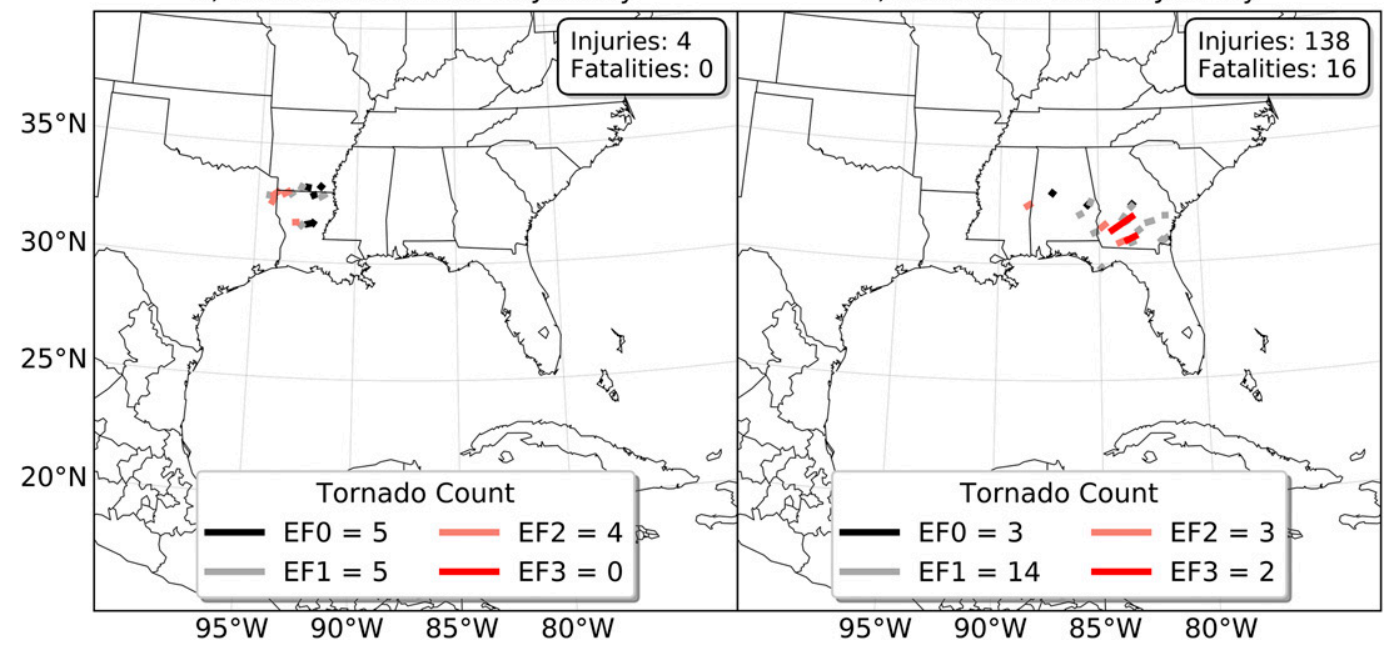

FIG. 1. (a) Geographical domain of the WRF Model simulations containing marine regions as delineated by the International Hydrographic Organization (Bekiashev and Serebriakov 1981). Tornado occurrence locations are also included and color coded by time period of occurrence as indicated in the legend: 0900-2100 UTC 21 Jan, 2100 UTC 21 Jan-0400 UTC 22 Jan, 0400-2300 UTC 22 Jan, and 0000-0900 UTC 23 Jan. Tornado paths are color coded by intensity [enhanced Fujita scale (EF)] and the number of injuries and fatalities are shown for (b) 0900 2100 UTC 21 Jan, (c) 2100-0400 UTC 21-22 Jan, and (d) 0400-2300 UTC 22 Jan.

of mesoscale features within WRF simulations, yet confine synoptic-scale details to those present in NARR that adequately capture the large-scale setting of the tornado outbreak. Spectral nudging has been used in numerous studies that have dynamically downscaled to convectionallowing resolutions across the CONUS (e.g., Liu et al. 2017). Spectral nudging was applied with each NARR input dataset, which has a 3-hourly resolution. Moisture was not nudged at any level to avoid contaminating the resultant influence of subsequent SST perturbations.

Parameters that correspond well with severe thunderstorm hazards (e.g., tornadoes, damaging winds, and severe hail) can be used to derive estimates of severe convection hazards in model simulations (e.g.,
Trapp et al. 2011; Clark et al. 2013; Robinson et al. 2013; Gensini and Mote 2014; Sobash et al. 2019). Similar to Trapp et al. (2011) and Gensini and Mote (2014), a model proxy for severe thunderstorm hazards was derived using hourly maximum updraft helicity $\left(\mathrm{UH} ; \mathrm{m}^{2} \mathrm{~s}^{-2}\right)$. $\mathrm{UH}$ is a proxy for the rotating updraft core of a supercell that can be quantified as

$$
\mathrm{UH}=\int_{2 \mathrm{~km}}^{5 \mathrm{~km}} w \zeta d z,
$$

where integration of the vertical components of velocity $w$ and vorticity $\zeta$ occur across a $2-5-\mathrm{km}$ depth (Kain et al. 2008). While UH can be a useful surrogate 
TABLE 1. WRF simulation configuration.

\begin{tabular}{lc}
\hline \multicolumn{1}{c}{ Simulation configuration } & All ensemble members \\
\hline Time step & $16 \mathrm{~s}$ \\
Horizontal grid spacing & $4 \mathrm{~km}$ \\
Vertical levels & 45, hybrid sigma-pressure \\
Model top & $100 \mathrm{hPa}$ \\
East-west number of grid points & 750 \\
North-south number of grid points & 700 \\
Spectral nudging wavenumber & 2 \\
Spectral nudging coefficient & 0.0003 \\
Map projection & Lambert Conformal Conic \\
Planetary boundary layer & Yonsei University (YSU) scheme (Hong et al. 2006) \\
Shortwave and longwave radiation & RRTMG (Mlawer et al. 1997) \\
Land surface & Noah-MP land surface model (Tewari et al. 2004) \\
Surface layer & Revised MM5 Monin-Obukhov scheme (Jiménez et al. 2012) \\
\hline
\end{tabular}

for tornado-producing storms, we note that past studies have found it to be more representative of modeled supercellular convection (Clark et al. 2013; Sobash et al. 2016), which can produce varied severe thunderstorm hazards (not just tornadoes; Jones et al. 2004; Trapp et al. 2005). As a tornado proxy, UH has proven more skillful when combined with other environmental precursors or smoothed and analyzed at coarser scales (Clark et al. 2013; Sobash et al. 2016; Gallo et al. 2016). Here we coarsened the grid spacing and applied a smoother, as described in the following paragraph. It could be argued that a lower UH vertical layer (e.g., 0-3 km) should be used for winter tornadoes that may be associated with shallower supercells (e.g., Sobash et al. 2016, 2019), but we found differences to be minimal.

A binary neighborhood approach was used for the tornado proxy (Schwartz and Sobash 2017), where a value of 1 was allotted to a grid cell when the UH threshold was exceeded, and a value of zero was assigned to a grid cell when the threshold was not exceeded. A spatial scale greater than the original WRF grid spacing (80-km neighborhood; 4-km original) was used for the binary field. An $80 \mathrm{~km} \times 80 \mathrm{~km}$ grid spacing was chosen as the neighborhood field because the area of each grid cell corresponds to the area used by the NOAA SPC in tornado probability forecasts (within 25 miles of a point; Brooks et al. 2003). The skill of various $\mathrm{UH}$ thresholds (e.g., $\geq 60 \mathrm{~m}^{2} \mathrm{~s}^{-1}$ ) were tested and will be further detailed in the results. Observed tornado reports during the 3 -day outbreak were binned onto grids of matching resolution $(80 \mathrm{~km} \times 80 \mathrm{~km})$ using dichotomous assignment (one or zero) to verify the skill of the model proxy derived from WRF simulations. We note that numerous widespread severe hail and wind reports also occurred during the tornado outbreak. However, we focused only on binary assignment of tornado report data for verification given that tornadoes had a much greater societal impact during this outbreak in terms of fatalities, economic losses, and property damage.

Scale normalized similarity (SNS; Trapp et al. 2011) was the preferred method to evaluate model skill in capturing tornadic convection hazards, as opposed to other methods like root-mean-square error (RMSE). RMSE can result in large error penalties in the presence of finescale spatial displacement between the model output and observations. SNS employs a "fuzzy" verification approach (Ebert 2008), in which a convolution kernel is applied to a binary field at increasingly coarser grid spacing to dampen error signals that emerge from small spatial offsets in the model output. SNS skill that increases as neighborhood size increases shows that the model was accurate in creating the event of interest with some spatial offset to the observed event. SNS is computed as

$$
\mathrm{SNS}_{(n)}=1-\frac{\mathrm{RMSE}_{\mathrm{ref}}}{\mathrm{RMSE}_{\mathrm{re}}}
$$

where $n$ is the neighborhood size of the binary grid during the respective convolution kernel pass and ref is a low-skill reference forecast (Murphy and Epstein 1989).

TABLE 2. WRF microphysics parameterizations for ensemble simulations.

\begin{tabular}{cl}
\hline \hline Ensemble & \multicolumn{1}{c}{ Microphysics parameterizations } \\
\hline 1 & $\begin{array}{c}\text { WRF single-moment 6-class (WSM6; Hong and } \\
\text { Lim 2006) } \\
\text { WRF double-moment 6-class (WDM6; Hong } \\
\text { et al. 2010) }\end{array}$ \\
3 & Thompson (Thompson et al. 2008) \\
4 & Thompson aerosol-aware (Thompson and \\
5 & Eidhammer 2014) \\
6 & NSSL double-moment 4-ice (Mansell et al. 2010) \\
& Morrison double-moment (Morrison et al. 2009) \\
\hline
\end{tabular}


SNS is similar to fraction skill score (Roberts and Lean 2008), but employs the use of RMSE as opposed to MSE. RMSE and RMSE ref $_{\text {are evaluated as }}$

$$
\begin{aligned}
\mathrm{RMSE} & =\left[\frac{1}{N} \sum_{i=1}^{N}\left(M_{i}-O_{i}\right)^{2}\right]^{1 / 2}, \\
\mathrm{RMSE}_{\text {ref }} & =\left[\frac{1}{N}\left(\sum_{i=1}^{N} M_{i}^{2}+\sum_{i=1}^{N} O_{i}^{2}\right)\right]^{1 / 2},
\end{aligned}
$$

where $O_{i}$ and $M_{i}$ are the observational and model gridpoint parameter values, respectively. The variable $N$ represents the number of native grid cells $(4 \mathrm{~km})$ within the larger neighborhood grid cell.

To explore the potential sensitivity of the 21-23 January 2017 convective event to variability of upstream SSTs, WRF simulations were generated with perturbed SSTs (e.g., Miglietta et al. 2017; He et al. 2018). These simulations were initialized using the same model configuration as ensemble member 2 (Tables 1 and 2), which was found to more accurately depict the tornado outbreak. This finding is detailed further in the WRF control simulation section. SSTs were perturbed by $-2.0^{\circ}$, $-1.5^{\circ},-1.0^{\circ},-0.5^{\circ},+0.5^{\circ},+1.0^{\circ},+1.5^{\circ}$, and $+2.0^{\circ} \mathrm{C}$, spanning the total simulation runtime across three distinct areas (Fig. 2). Detailed discussion of the spatial features of the SST perturbed runs will be primarily focused on the $-2^{\circ},-1^{\circ},+1^{\circ}$, and $+2^{\circ} \mathrm{C}$ simulations given result consistency among runs of half-degree increments. The primary purpose of the $0.5^{\circ} \mathrm{C}$ increment simulations $\left( \pm 0.5^{\circ}, \pm 1.5^{\circ} \mathrm{C}\right)$ was to test whether the changes to tornado activity were consistent among ensemble members or simply noise (e.g., Ancell et al. 2018). We note that WRF was not run as a fully coupled atmosphere-ocean model and that SSTs were prescribed. The perturbed SST areas include the Caribbean Sea and Yucatán Channel (peak MU area; Figs. 2a,d,g,j), the northeast GoM (Figs. 2b,e,h,k), and the GoM basin (Figs. 2c,f,i,l). A consequence of forcing temperatures in this manner is that sharp horizontal temperature gradients could form between perturbed and nonperturbed SSTs. Therefore, a 2D Gaussian smoother (with a standard deviation of $120 \mathrm{~km}$ ) was applied along these boundaries and perturbed SST areas to ameliorate nonphysical boundaries.

Hourly tornadic storm proxy fields $(80 \mathrm{~km} \times 80 \mathrm{~km})$ were derived from the SST-perturbed simulations using dichotomous assignment, with a value of 1 assigned to a grid cell when UH exceeded a specified threshold, which varied from 40 to $100 \mathrm{~m}^{2} \mathrm{~s}^{-2}$. Despite a UH threshold of $80 \mathrm{~m}^{2} \mathrm{~s}^{-2}$ performing with greater skill than other thresholds (as evaluated using SNS), $60 \mathrm{~m}^{2} \mathrm{~s}^{-2}$ was used because it provides a larger sample size of severe grid cells that result in more robust statistics, and still provides skill in representing severe thunderstorm activity. The binary proxy was subsequently aggregated from 0900 UTC 21 January to 0900 UTC 23 January and differences compared among SST-perturbed runs to quantify possible changes in surrogate tornadic activity. Fields of predicted environmental variables for the various SST perturbed simulations were explored to determine the potential causes for changes in simulated convection morphology and surrogate tornado activity. Pearson and Spearman's rank correlation coefficients were computed between the SST perturbations and the percent changes in tornado proxy to quantify the SST influence on tornado activity.

\section{Results}

\section{a. Synoptic and mesoscale overview}

The mesoscale and synoptic evolution of the multiday tornado outbreak can be separated into four distinct temporal periods for simplicity (Fig. 1a). During the first, a shortwave trough across the Missouri Valley and lower Mississippi Valley, embedded within a largerscale trough, approached the central Gulf Coast on the morning of 21 January 2017 (Fig. 3a). Southerly surface winds transported rich low-level moisture from the GoM region northward (Fig. 3b), characterized by surface dewpoint temperatures of about $20^{\circ} \mathrm{C}$. Nontornadic severe convection initiated across southeast Texas by 0000 UTC 21 January and continued spreading eastward overnight. East of ongoing convection, several rightmoving discrete supercells initiated over southern Louisiana and Mississippi by 0800 UTC and moved eastward into the warm sector over the Southeast (feature A in Figs. 4a,b). The warm sector contained sufficient vertical instability for convective development (500-1000 J kg ${ }^{-1}$ MLCAPE; Fig. 3a). One of these discrete supercells produced the first tornado (Figs. 1a,b) of the multiday event at approximately 0900 UTC in southern Mississippi $\left(31^{\circ} \mathrm{N}, 89^{\circ} \mathrm{W}\right)$ and resulted in 4 fatalities, more than 50 injuries, and was subsequently rated EF3 [Enhanced Fujita scale (EF); Potter 2007; Edwards et al. 2013]. Convective activity continued during the following hours, as a mesoscale convective system developed and moved into southern Alabama. A southerly low-level jet intensified and $0-6-\mathrm{km}$ vertical shear increased to $\geq 50 \mathrm{kt}$ across eastern Alabama and Georgia (not shown). The multimode convection (supercell and multicell storms) evolved into a quasi-linear convective system (QLCS) during this time period with embedded mesovortices (feature A in Fig. 4d). Favorable thermodynamic and 
a) Peak MU: $-2^{\circ} \mathrm{C}$

b) NE GoM: $-2^{\circ} \mathrm{C}$

c) Full GoM: $-2^{\circ} \mathrm{C}$

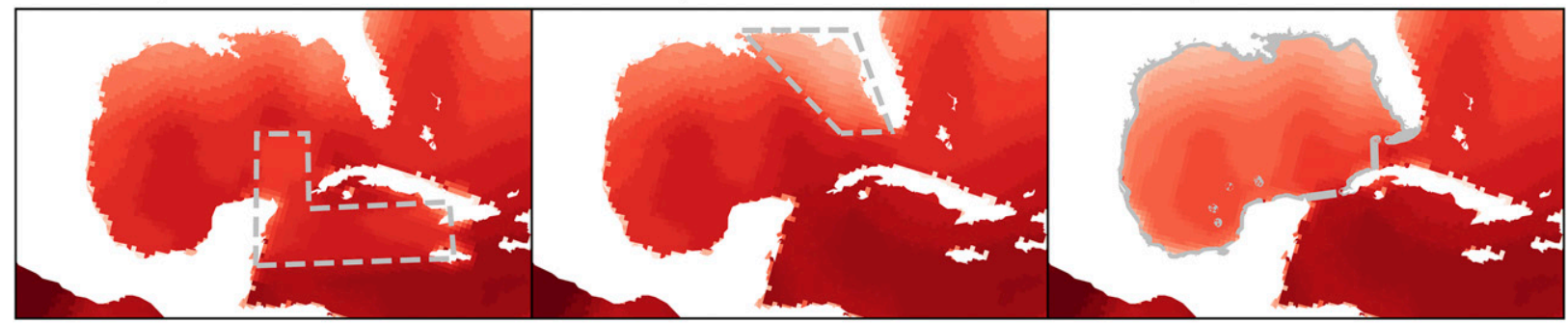

d) Peak MU: $-1^{\circ} \mathrm{C}$

e) NE GoM: $-1^{\circ} \mathrm{C}$

f) Full GoM: $-1^{\circ} \mathrm{C}$

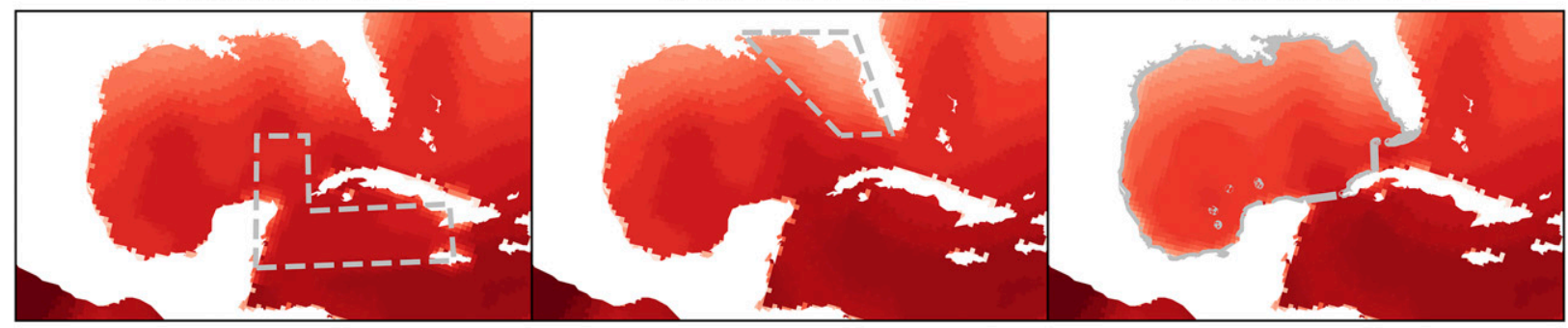

g) Peak MU: $+1^{\circ} \mathrm{C}$

h) NE GoM: $+1^{\circ} \mathrm{C}$

i) Full GoM: $+1^{\circ} \mathrm{C}$

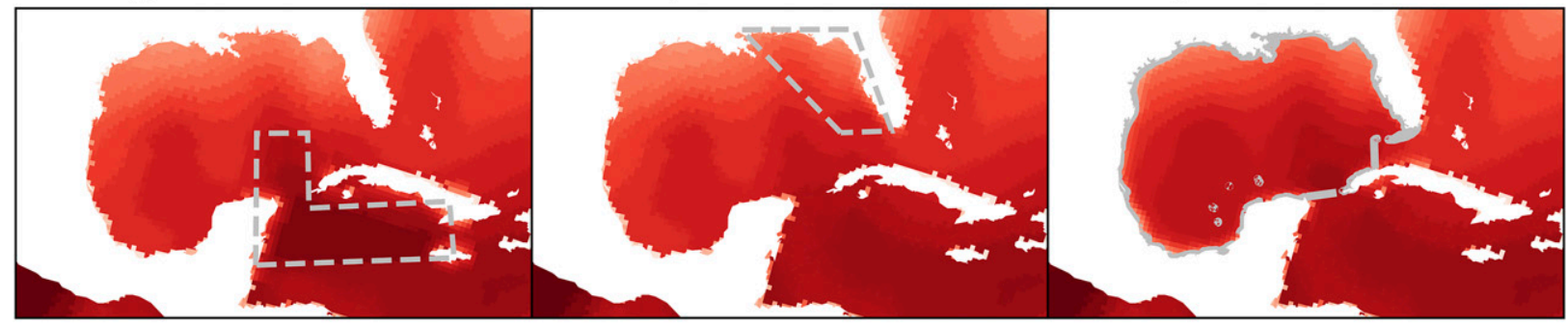

j) Peak $\mathrm{MU}:+2^{\circ} \mathrm{C}$

k) NE GoM: $+2{ }^{\circ} \mathrm{C}$

I) Full GoM: $+2{ }^{\circ} \mathrm{C}$

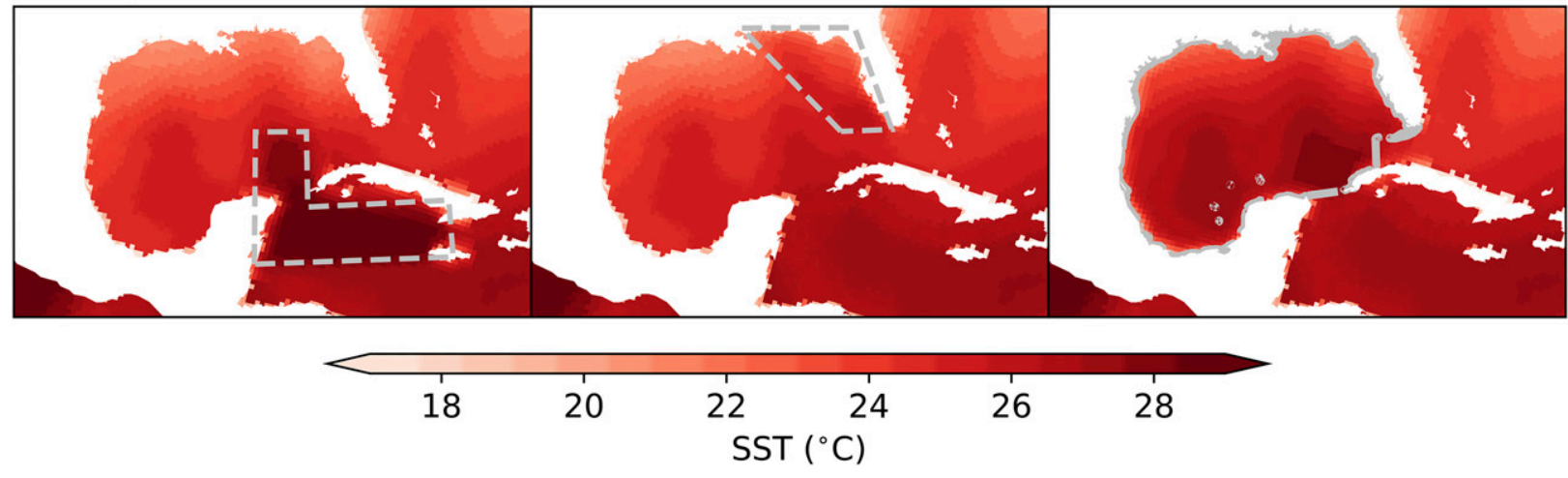

FIG. 2. Smoothed SST $\left({ }^{\circ} \mathrm{C}\right)$ input for various temperature perturbations and regions as indicated in the figure. SST perturbed areas are shown with a gray dashed line and include the (a),(d),(g),(j) peak moisture uptake areas; (b),(e),(h),(k) northeast GoM; and (c),(f),(i),(l) GoM basin.

kinematic profiles led to an active tornadic period (1100-2100 UTC), consisting of more than 40 tornadoes that impacted Alabama, Georgia, and South Carolina (Figs. 1a,b).

Large-scale cyclogenesis continued to unfold with deep troughing present by 2100 UTC 21 January across the eastern CONUS (Fig. 3c). This second period of interest during the outbreak (Figs. 1a,c) is characterized by a deepening upper-level low and another shortwave impulse that aided in the generation of another surface low in the ArkLaTex region (Arkansas, Louisiana, and Texas). Discrete supercells developed in the warm sector (Fig. 4e) and produced 14 tornadoes across the ArkLaTex through 0300 UTC 22 January (Figs. 1a,c). 
a) 0300 UTC 21 Jan

b) 0900 UTC 21 Jan

c) 1500 UTC 21 Jan

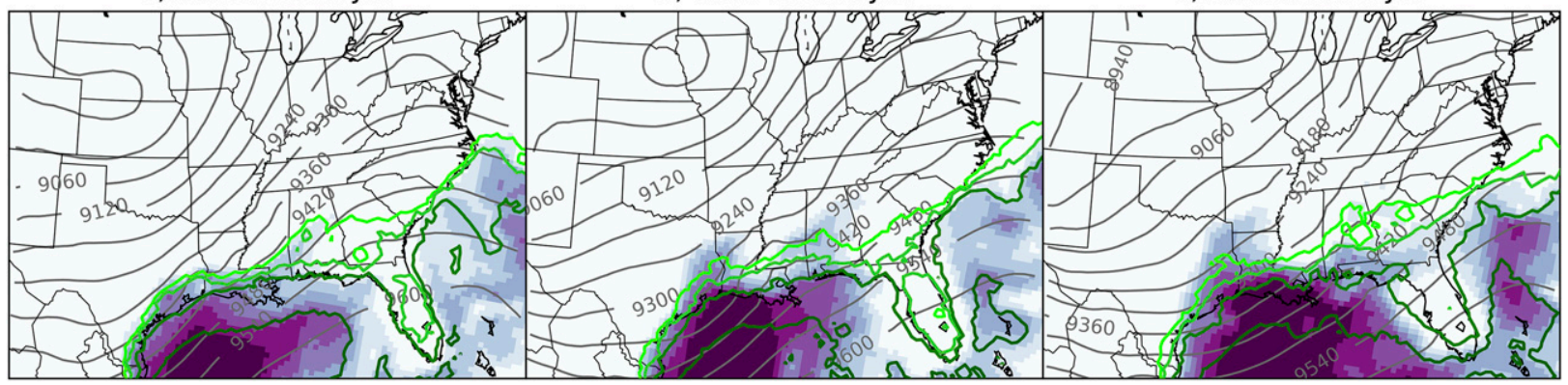

d) 2100 UTC 21 Jan

e) 0300 UTC 22 Jan

f) 0900 UTC 22 Jan

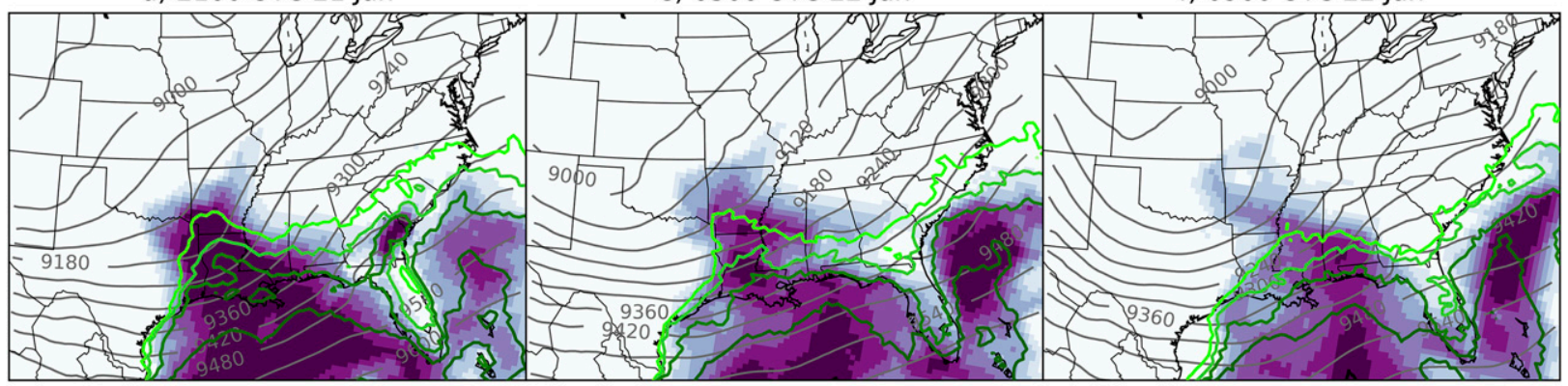

g) 1500 UTC 22 Jan

h) 2100 UTC 22 Jan

i) 0300 UTC 23 Jan

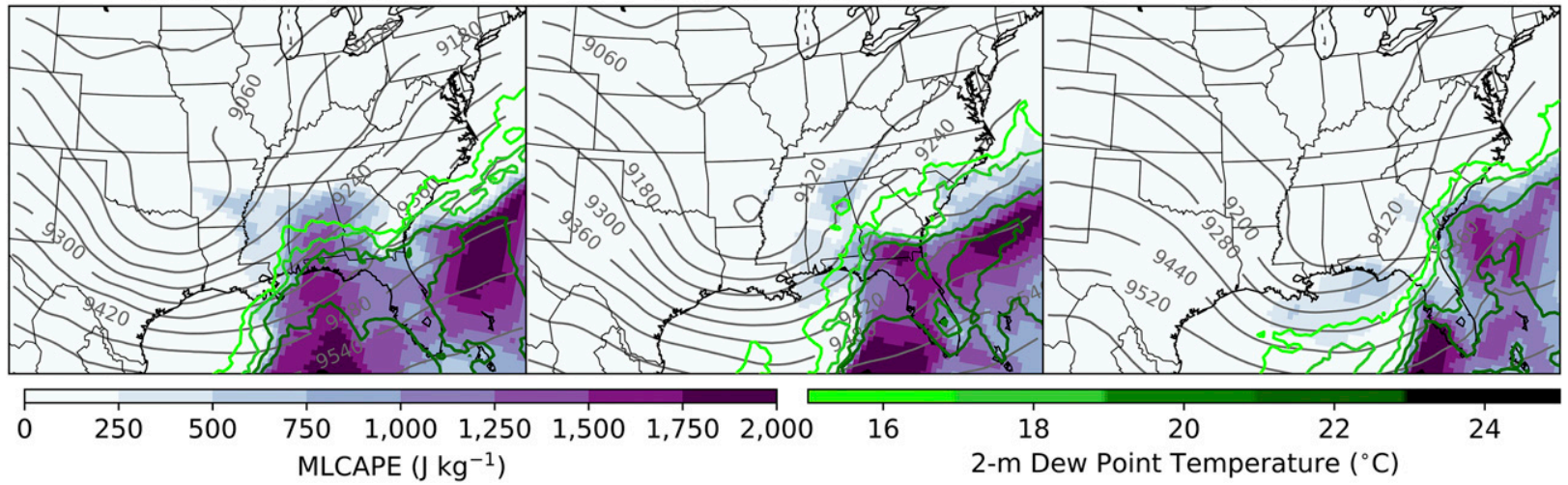

FIG. 3. NARR during select times of the 21-23 Jan 2017 tornado outbreak: (a) 0300 UTC 21 Jan, (b) 0900 UTC 21 Jan, (c) 1500 UTC 21 Jan, (d) 2100 UTC 21 Jan, (e) 0300 UTC 22 Jan, (f) 0900 UTC 22 Jan, (g) 1500 UTC 22 Jan, (h) 2100 UTC 22 Jan, and (i) 0300 UTC 23 Jan. Variables shown include 300-hPa geopotential height (m; contours), mixed-layer convective available potential energy (MLCAPE; $\mathrm{J} \mathrm{kg}^{-1}$ ), and 2-m dewpoint temperature $\left({ }^{\circ} \mathrm{C}\right)$.

Farther east, rapid air mass recovery was underway across the Southeast (Fig. 3e) and thus marks the start of the third time period of interest during the outbreak (Fig. 1a). Convective parameters became favorable for tornadic thunderstorms, including $20^{\circ} \mathrm{C}$ surface dewpoints and $500-1250 \mathrm{~J} \mathrm{~kg}^{-1}$ MLCAPE. By 0300 UTC 22 January, surface-based discrete and semidiscrete supercells were already underway from southern Mississippi to southern Georgia (feature B in Fig. 4e). As the trough continued moving east, an associated cold front served as a source of vertical ascent, which assisted the development of a line of supercells and supercell clusters across the Florida Panhandle and southern Georgia in the wake of previous convection (features C and D in Figs. 4g,h). Over this 19-h period (0400-2300 UTC 22 January), 22 tornadoes occurred across Mississippi, Alabama, and Georgia (Figs. 1a,d). The cold front continued moving southeast across the Florida Peninsula, with high moisture and $1000 \mathrm{~J} \mathrm{~kg}^{-1}$ MLCAPE preceding it. Three tornadoes occurred during this final time period of interest (Fig. 1a) over Florida on 0600-0900 UTC 23 January before the event ended (feature D in Fig. 4i).

\section{b. January 2017 Gulf of Mexico record warmth}

January 2017 was the warmest January month for average SSTs in the GoM basin (1982-2019; Fig. 5a). 
a) 0300 UTC 21 Jan

b) 0900 UTC 21 Jan

c) 1500 UTC 21 Jan
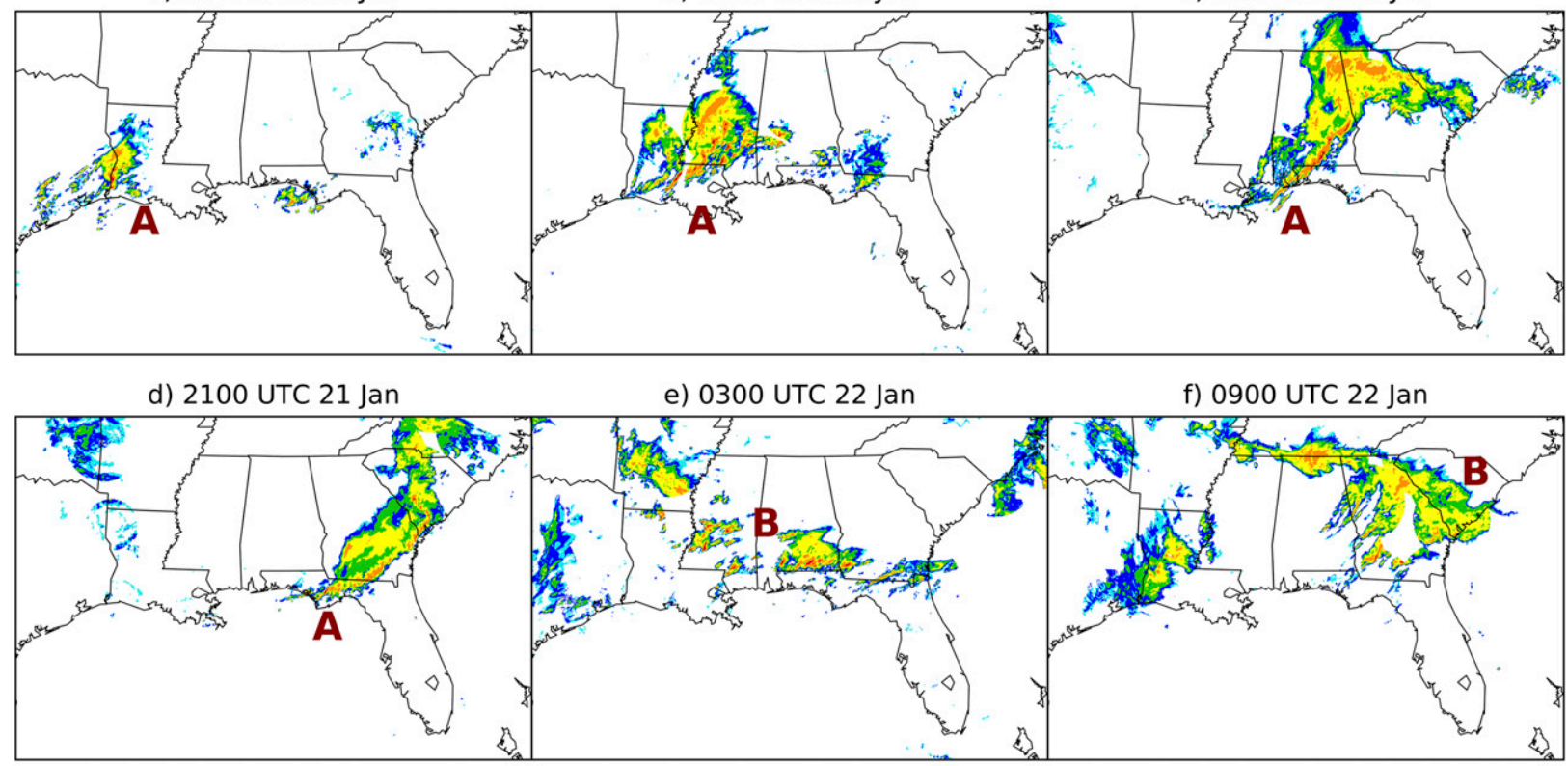

g) 1500 UTC 22 Jan

h) 2100 UTC 22 Jan

i) 0300 UTC 23 Jan

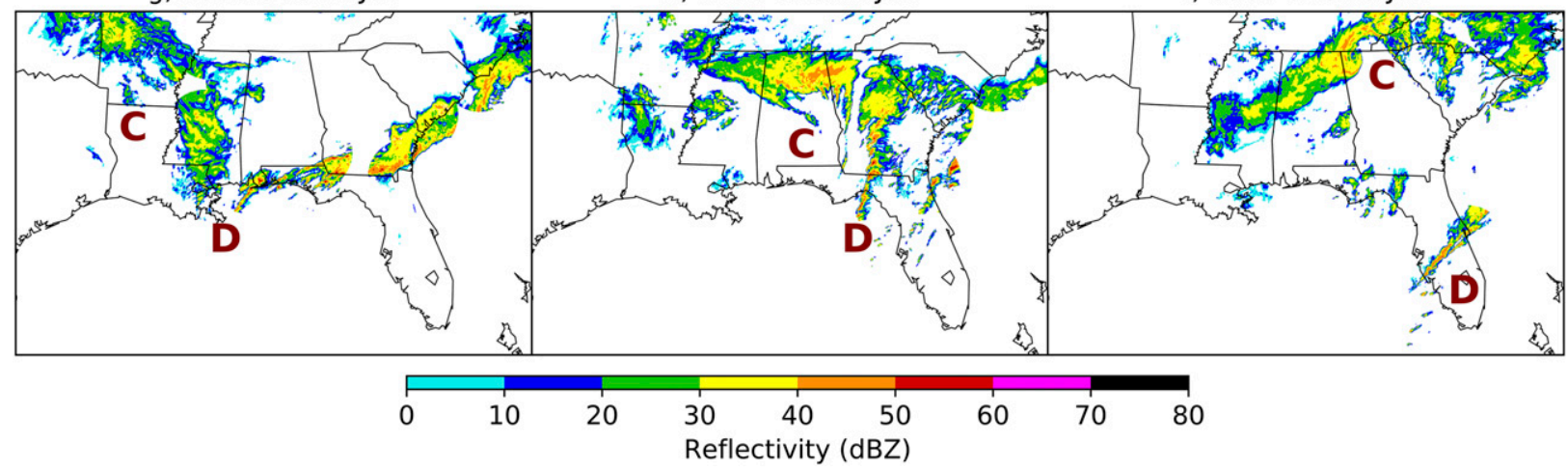

FIG. 4. GridRad data containing merged and quality controlled Next Generation Radar (NEXRAD) Weather Surveillance Radar-1988 Doppler (WSR-88D) Level II radar reflectivity (at all available radar azimuth scans) for (a) 0300 UTC 21 Jan, (b) 0900 UTC 21 Jan, (c) 1500 UTC 21 Jan, (d) 2100 UTC 21 Jan, (e) 0300 UTC 22 Jan, (f) 0900 UTC 22 Jan, (g) 1500 UTC 22 Jan, (h) 2100 UTC 22 Jan, and (i) 0300 UTC 23 Jan. Letter annotations refer to features of interest discussed in text.

In the days leading up to the tornado outbreak, GoM SSTs were $\geq 24^{\circ} \mathrm{C}$ and SSTAs across the far northern and northeastern $\mathrm{GoM}$ were $\geq+3^{\circ} \mathrm{C}$ (15-22 January 2017; Figs. 5b,c). Of particular interest was a region of positive SSTAs across the northeastern GoM with proximity to northwest Florida, Alabama, and Georgia, where the most intense portions of the tornado outbreak occurred (Fig. 5c). SSTAs across this region increased by more than $+0.5^{\circ} \mathrm{C}$ during 15-21 January. The northeast GoM warmth could be related to the influence of the Loop Current (Vukovich 2007), which is a deep reservoir of warm water with tropical origins, previously associated with increased moisture flux (Molinari 1987) and increased severe thunderstorm activity over the Southeast (Molina et al. 2016). Exploring the specific reasons for GoM basinwide warmth are beyond the scope of this study. Within the basinwide warmth of the GoM, negative SSTAs were located just north of the Yucatán Channel (Fig. 5c). The reason for this is unclear, but given its proximity to the Loop Current, it could be related to ocean currents. After the 3-day tornado outbreak, GoM basin surface waters cooled due to the passage of a cold front (Fig. 5a). Before partly attributing the tornado outbreak of 21-23 January 2017 to anomalously warm GoM SSTs, further analysis is needed. Moisture could have originated from bodies of water at more remote distances from the CONUS, such as the Caribbean Sea (Molina and Allen 2019), and localized cool SSTAs could have reduced heat and moisture fluxes onto overlying air masses. A Lagrangian-based moisture attribution method 
a) GoM Basin Daily SSTs
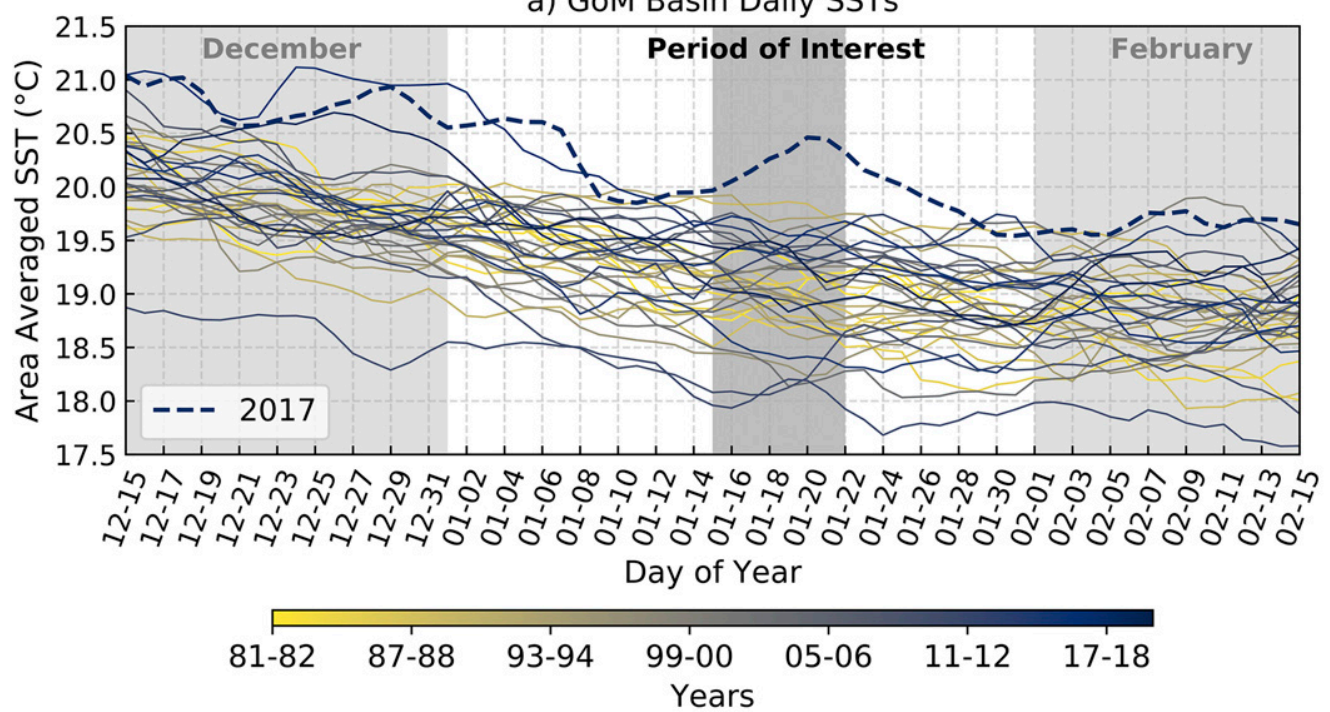

b) Mean SSTs (15-22 Jan 2017)

c) Mean SSTAs (15-22 Jan 2017)

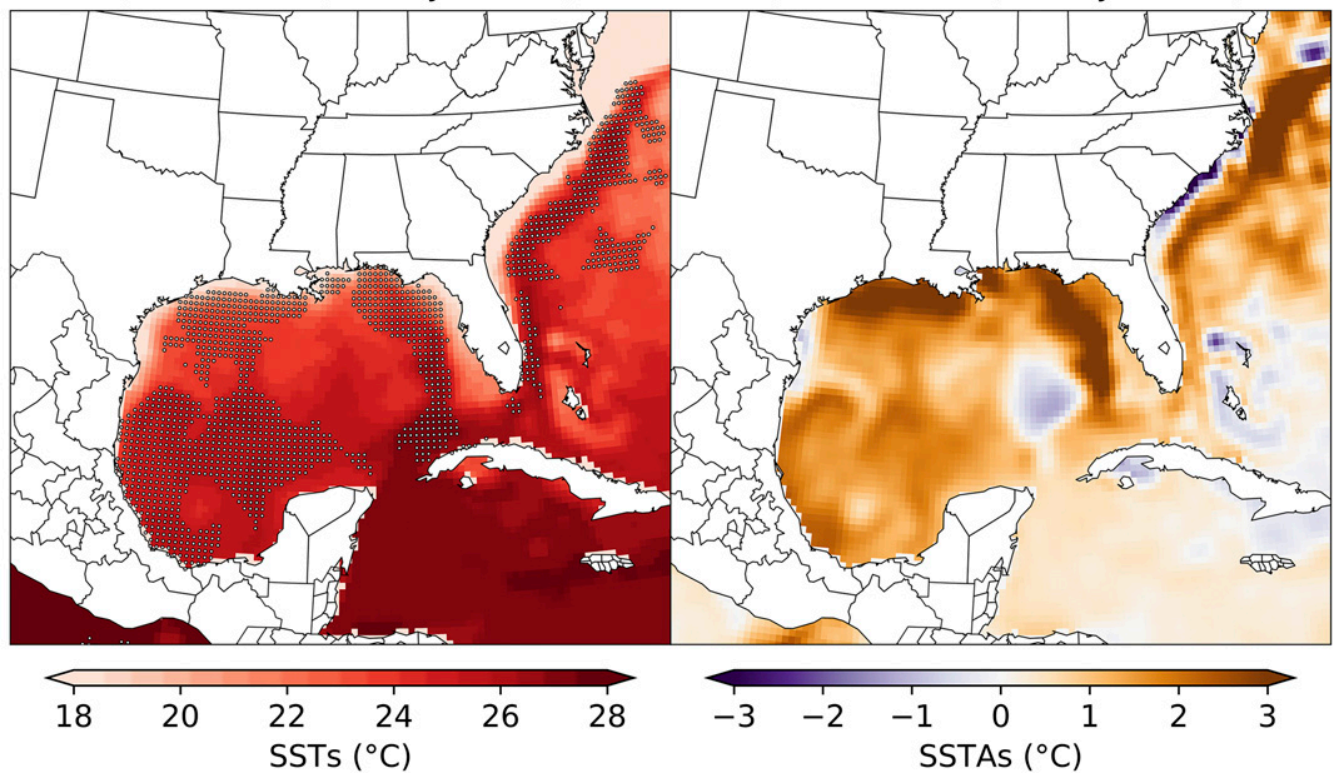

FIG. 5. (a) Gulf of Mexico (GoM) basin area-averaged SSTs $\left({ }^{\circ} \mathrm{C}\right)$; the dashed line represents the year of the case study tornado outbreak (2017). (b),(c) SSTs and SST anomalies (SSTAs) for the GoM, Caribbean Sea, and North Atlantic Ocean (1982-2019). Stippling in (b) indicates grid boxes with record-warm SSTs.

follows to quantitatively determine whether moisture originated from anomalously warm GoM surface waters.

\section{c. Moisture attribution}

HYSPLIT backward trajectories initiated from the 21-23 January 2017 tornadoes show that air parcels traveled across the GoM before reaching the Southeast (Fig. 6a). Air parcels were primarily advected across the eastern GoM, Yucatán Channel, and northwestern Caribbean Sea (Fig. 6a), with advection likely driven by synoptic-scale features associated with the tornado outbreak (e.g., low-level winds in response to surface cyclogenesis). Air parcels generally descended toward lower elevations as they entered the Yucatán Channel on approach to the Southeast, coming into closer proximity with the sea surface (Fig. 7). Horizontal moisture flux peaked across the Yucatán Channel and eastern GoM, which suggests that the moisture content of air masses increased while in relative proximity to the CONUS (Fig. 6b). This result is corroborated by MU results; nearly $83.7 \%$ of surface moisture contributions to the 21-23 January 2017 tornadic storms originated 
a) Frequency: 21-23 Jan

b) MF: 21-23 Jan

c) MU: $21-23 \mathrm{Jan} \rightarrow 10 \frac{\mathrm{m}}{\mathrm{s}}$
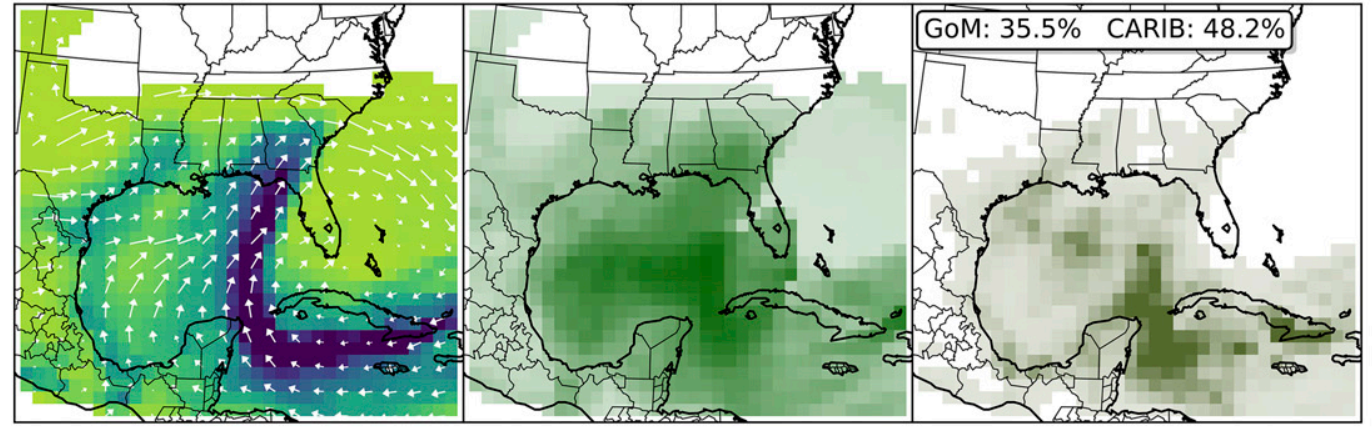

d) Frequency: 21 Jan

e) MF: 21 Jan

f) MU: 21 Jan
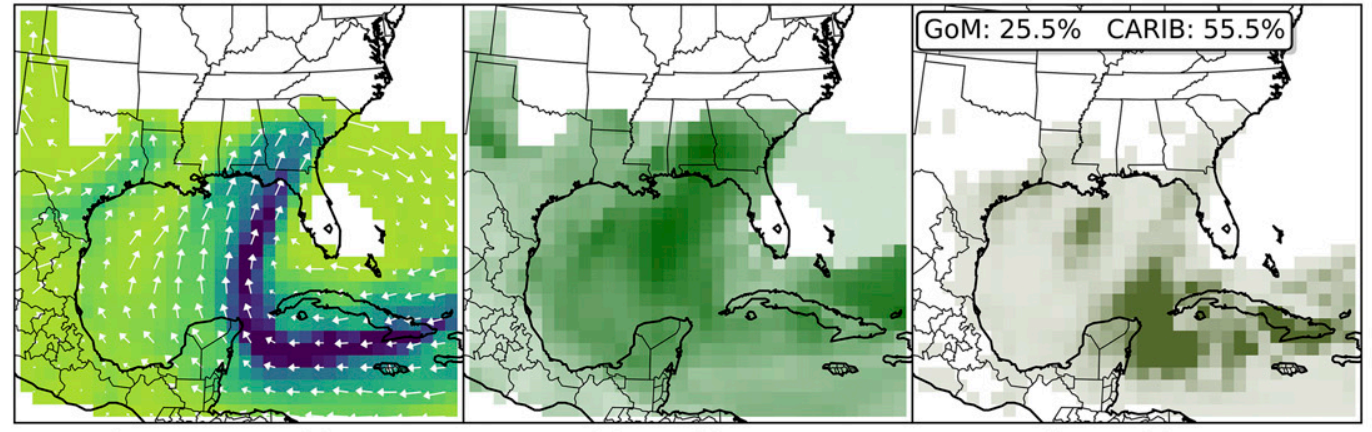

g) Frequency: 22 Jan

h) MF: 22 Jan

i) MU: 22 Jan

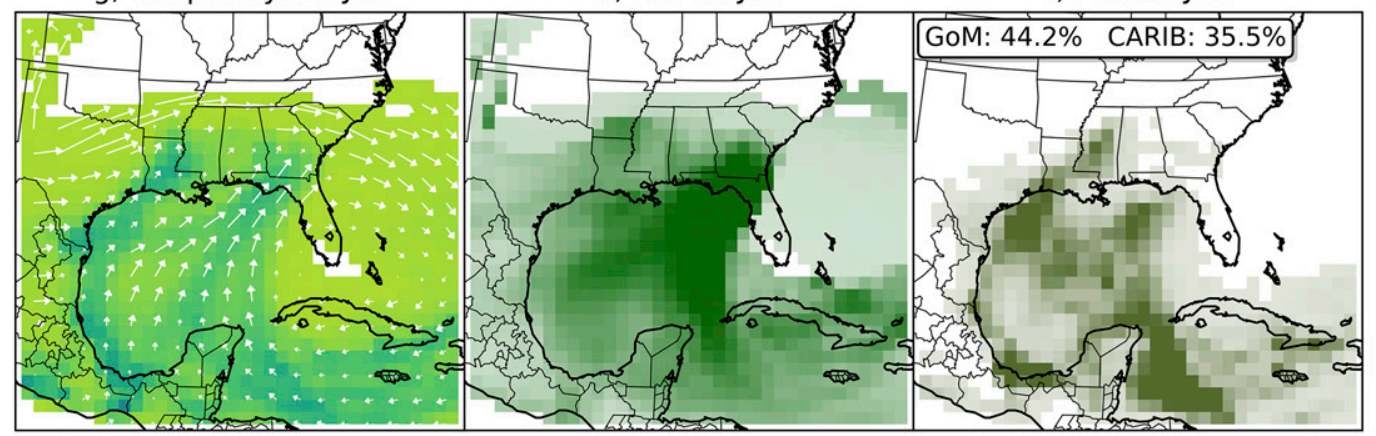

j) Frequency: 23 Jan

k) MF: 23 Jan

I) MU: 23 Jan
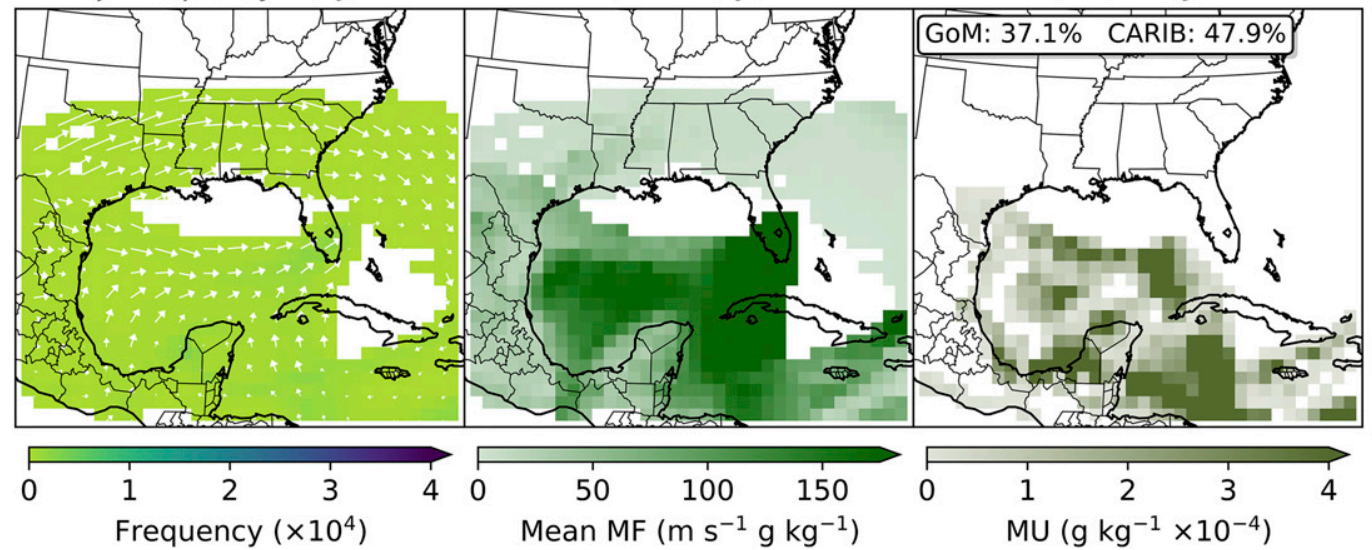

FIG. 6. HYSPLIT results computed from NARR stratified by date of tornado occurrence: (a)-(c) 21-23 Jan, (d)-(f) $21 \mathrm{Jan},(\mathrm{g})-(\mathrm{i}) 22 \mathrm{Jan}$, and (j)-(1) $23 \mathrm{Jan}$. Binned $(80 \mathrm{~km} \times 80 \mathrm{~km})$ variables shown include (left) trajectory frequency (total trajectory intersections per grid cell); (center) horizontal moisture flux (MF; $\mathrm{m} \mathrm{s}^{-1} \mathrm{~g} \mathrm{~kg}^{-1}$ ); and (right) frequency weighted moisture uptake (MU; $\mathrm{g} \mathrm{kg}^{-1}$ ). White arrows represent mean directional flow of trajectories in (a), (d), (g), and (j). MU percent contribution per marine basin (GoM and CARIB) shown in (c), (f), (i), and (l). 
a) 09-21 UTC 21 Jan

b) 21-04 UTC 21-22 Jan

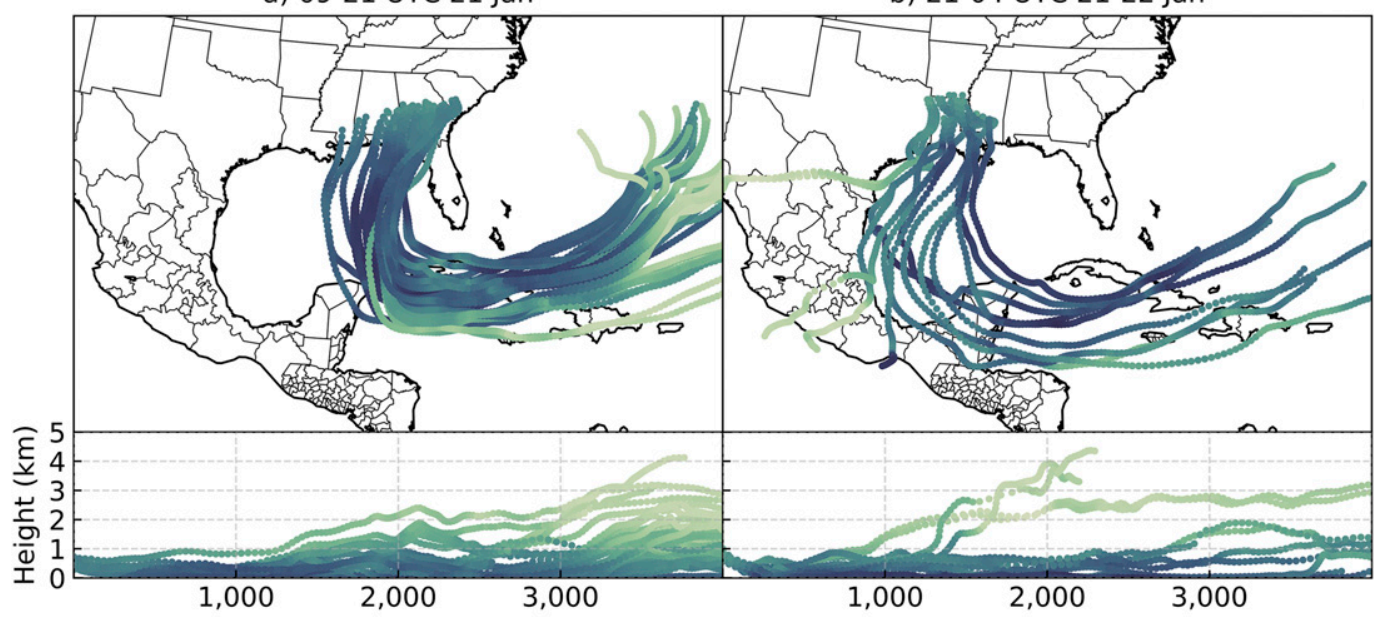

c) 04-23 UTC 22 Jan

d) 00-09 UTC 23 Jan

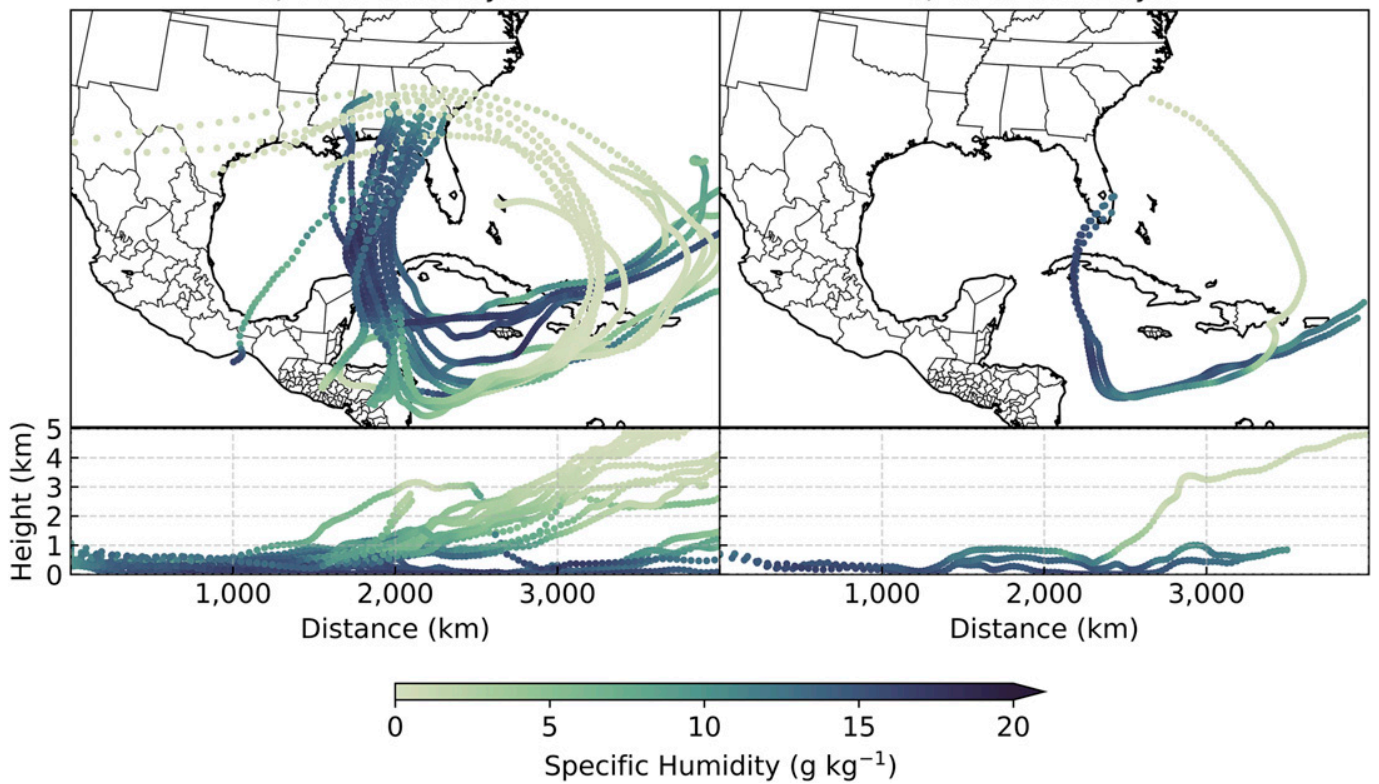

FIG. 7. HYSPLIT backward trajectories initialized from tornado reports of 21-23 Jan 2017. Trajectories were separated into four temporal groups, as delineated in Fig. 1: (a) 0900-2100 UTC 21 Jan, (b) 2100-0400 UTC 21-22 Jan, (c) 0400-2300 UTC 22 Jan, and (d) 0000-0900 UTC 23 Jan. One trajectory per 3D matrix is shown for visualization purposes (centered on the report location and at an altitude of $0.5 \times \mathrm{HPBL}$ ).

from the GoM and Caribbean Sea (35.5\% from GoM; $48.2 \%$ from Caribbean Sea; Fig. 6c) at approximately 25-100 $\mathrm{h}$ before initiation of the outbreak's first tornado (not shown). Peak moisture contribution origins coincide with the region frequented by the GoM Loop Current (Vukovich 2007). This result suggests that warm Loop Current waters can supply moisture to the CONUS and contribute to the development of severe convection (Molina and Allen 2019).

Moisture source regions for tornadic storms varied by day (Figs. 6d-1, 7). Moisture contributions to tornadoes of 21 January (Figs. 6f, 7a) predominantly originated from the northwest Caribbean Sea (55.5\%) and GoM $(25.5 \%)$. In contrast, moisture contributions to tornadoes of 22 January (Figs. 6i, 7b,c) were more proximal to the CONUS, primarily originating from the GoM $(44.2 \%)$ and northwest Caribbean Sea (35.5\%). The moisture origins of 23 January tornadoes (Figs. 61, 7d) were primarily from the Caribbean Sea $(47.9 \%)$ and GoM (37.1\%). These differences are likely related to the timing and positioning of synoptic-scale features associated with the tornado outbreak (e.g., large-scale troughing and associated low-level southerly wind streams) and the corresponding locations from which 
trajectories were initiated (e.g., Fig. 1). For example, maximum trajectory frequency is greater on 21 January than 22 and 23 January for two reasons: (i) more tornadoes occurred on 21 January and (ii) tornadoes occurred in closer proximity to each other on 21 January, resulting in reduced dispersion of trajectories and thus more grid cell intersections (e.g., Fig. 7a). We note that large magnitude SSTAs across the northeastern GoM do not coincide with peak MU areas (Figs. 6c,f,i,l), but do overlap large magnitudes of meridional moisture transport (Figs. 6b,e,h,k). This result suggests that air parcels had generally reached thermodynamic equilibrium and maximum moisture content prior to reaching the northeast GoM (Molina and Allen 2020), limiting additional moisture acquisition over this region (Fig. 7). However, this result is subject to the limitations of the MU algorithm and its inherent assumptions, including the vertical delimiter (HPBL) used to identify locations of uptake. For example, some air parcels could have risen above the HPBL and subsequent moisture increases would not have been denoted as surficial.

\section{d. WRF control simulation}

Convection generated by the six ensemble members with nonperturbed SSTs (Table 2) resembles observed radar reflectivity and convective morphology. These similarities are likely because the 21-23 January 2017 tornado outbreak can be characterized by strong largescale forcing (e.g., trough and cold-front). The application of spectral nudging on synoptic-scale features during the full-simulation runtime (forecast hours 0-192) also likely further constrained variability among ensemble members. All ensemble members show strongly forced convection initiating along the Louisiana and Mississippi coastline prior to 0900 UTC 21 January and the subsequent mixed convective modes that progress across the Southeast through 2100 UTC (not shown). However, the 0900 UTC 21 January discrete convective mode was most accurately depicted by ensemble member 2 (Fig. 8), given that other ensemble members exhibited farther east displacement of convection and upscale growth early during the event onset (not shown). Proper convection morphology depiction early in the modeled tornado outbreak is important given that subsequent convection and environment modulations can be influenced by earlier thunderstorms. The second wave of convection was initiated across the ArkLaTex by all ensemble members with some subtle variations in mesoscale details, along with the frontal passage across Florida on 23 January.

SNS (Trapp et al. 2011) is a method used to evaluate model skill in capturing tornadic activity. However, we note that this technique also introduces uncertainty given that a single UH threshold will be unable to capture all instances of modeled tornadic activity within each WRF simulation. In an attempt to quantify tornadic storm proxy uncertainty, SNS was computed for various UH thresholds and all ensemble members, against gridded tornado report data (Table 3). As expected, as neighborhood size increases, model skill in matching tornado reports increases asymptotically for all microphysics parameterizations and tornadic convection proxies (Fig. 9). However, two ensemble members generally score higher SNS skill with smaller neighborhood sizes than the others (Figs. 9b,e): ensemble member 2 and ensemble member 5. However, ensemble member 5 displays greater sensitivity to the UH threshold chosen (Fig. 9e), in contrast to ensemble member 2 which shows greater result consistency (Fig. 9b, Table 3).

Closer analysis of ensemble member 2 shows that convection broadly corresponds to observational radar reflectivity for the event (cf. Figs. 4, 8). Similar to observed radar, the initial cluster of discrete supercells (Fig. 8b) evolves into a QLCS before reaching the Carolinas (Fig. 8d). The cold front and associated thunderstorms also cross Florida at approximately the same time as radar observations (Figs. $4 \mathrm{i}, 8 \mathrm{i}$ ). It is important to acknowledge that there are some disparities between the simulated radar reflectivity of ensemble member 2 and observational radar. For example, the initial cluster of convection is displaced farther east by about $200 \mathrm{~km}$ (Figs. 4b, 8b), which may have contributed to the errors between the modeled event tornado proxy and gridded tornado reports. Convection coverage is also more sparse across Florida during the frontal passage as compared to observations (Figs. 4g-i, 8g-i). We believe ensemble member 2 provides a sufficiently accurate depiction of the event. Ensemble member 2 will be used as the baseline ("control run") in the SST perturbations that follow. Previous studies (e.g., Clark et al. 2013; Sobash et al. 2019) have shown that a probabilistic ensemble approach can provide a range of solutions that account for uncertainties in convective-allowing model simulations and the chaotic nature of atmospheric processes, but we chose a deterministic approach due to computational constraints.

\section{e. SST sensitivity analysis: Predicted tornadic thunderstorm activity}

The cumulative sum of the hourly tornadic convection proxy derived using $\mathrm{UH} \geq 60 \mathrm{~m}^{2} \mathrm{~s}^{-2}$ was computed for each of the perturbed SST simulations to detect potential percent changes in tornado activity from the control run. Table 4 reveals that the percent change in predicted tornadic thunderstorm activity is nonlinear with regards to cooling and warming of upstream SSTs. For example, both cooling and warming of the northeast GoM produced increases and decreases to the tornado activity 
a) 0300 UTC 21 Jan

b) 0900 UTC 21 Jan

c) 1500 UTC $21 \mathrm{Jan}$

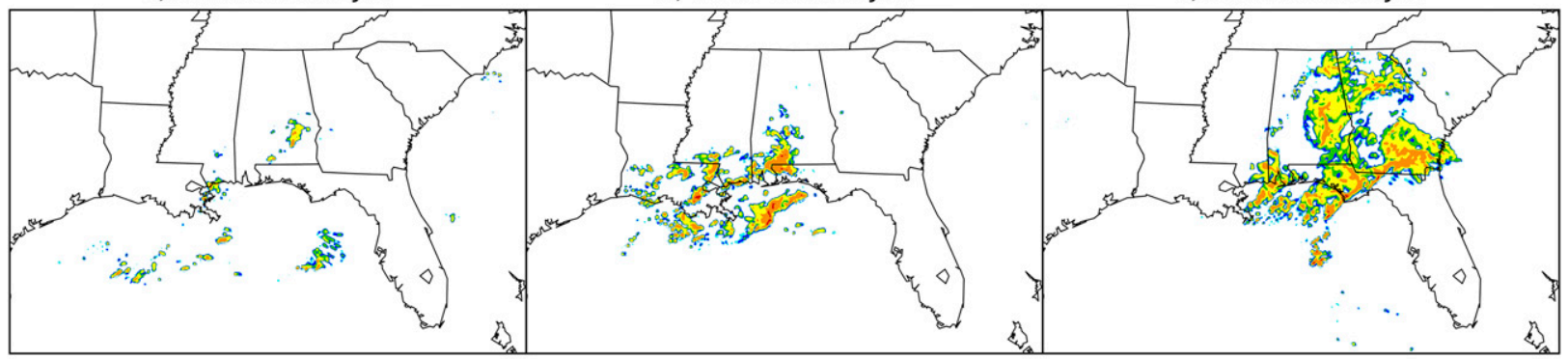

d) 2100 UTC 21 Jan

e) 0300 UTC 22 Jan

f) 0900 UTC 22 Jan

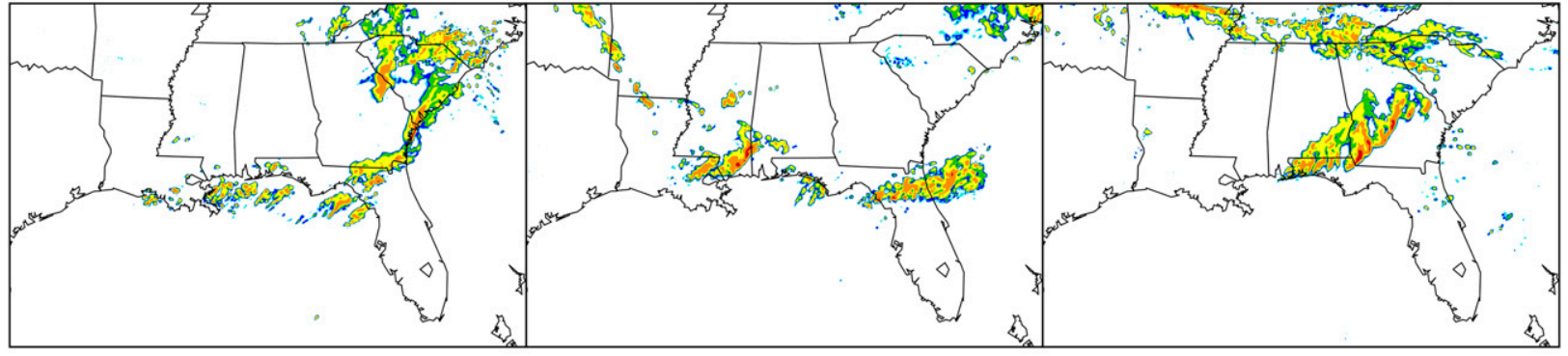

g) 1500 UTC 22 Jan

h) 2100 UTC 22 Jan

i) 0300 UTC $23 \mathrm{Jan}$

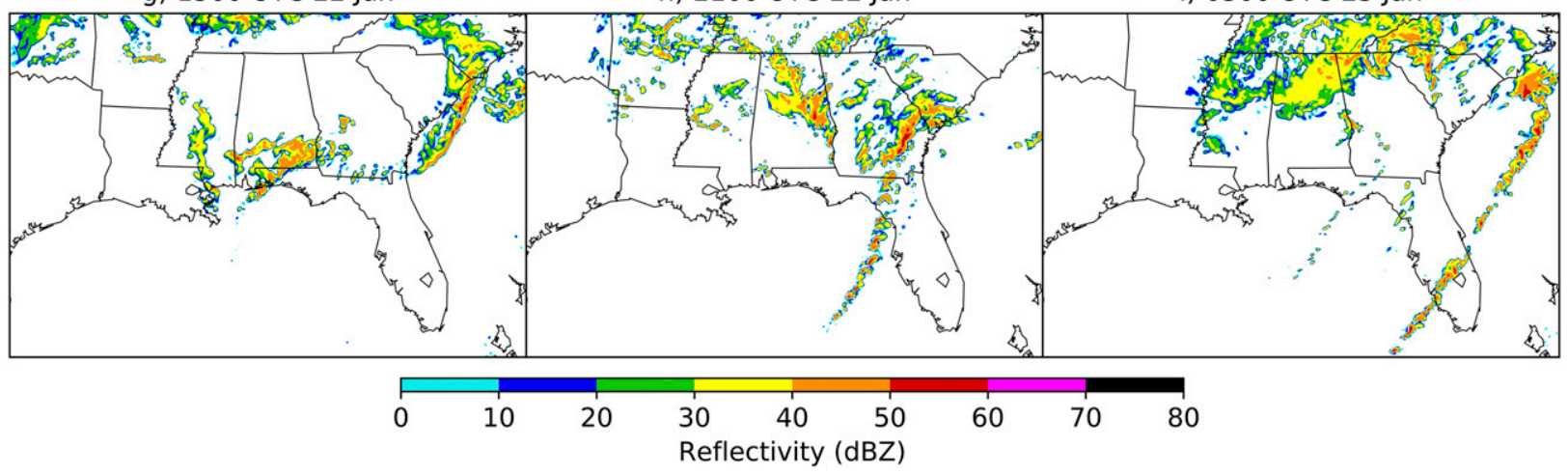

FIG. 8. WRF control run (ensemble member 2 in Table 2) simulated 2-km (AGL) radar reflectivity of the tornado outbreak at various times to illustrate convection morphology evolution. Time periods shown are as in Fig. 4.

proxy (Table 4 , middle). Stratifying the proxy percent change into 12-h time periods reveals that cooling of peak MU areas and the northeast GoM is associated with decreased tornado activity during 0900-2100 UTC 21 January, while warming in these regions is associated with increased tornado activity over the same period. These results are also reflected in positive correlation coefficients between the changes in tornado proxy and the Peak MU $(+0.85$ Pearson and +0.8 Spearman's rank) and northeast GoM $(+0.58$ Pearson and +0.54 Spearman's rank) SST perturbations. However, tornado proxy percent changes become ambiguous thereafter. This increased ambiguity later during the event could be related to ongoing convection modifying local environments, or that the quality of moisture return and Gulf SSTs were not as important later in the event, once the region had a high moisture content and air masses were able to recover more easily (Table 4, top and middle). Thus, the physical processes that influence air mass characteristics which precondition a tornadic environment possibly become less important later during the

TABLE 3. Maximum and mean scale normalized similarity (SNS) values for all UH thresholds $\left(100,90,80,70,60,50\right.$, and $\left.40 \mathrm{~m}^{2} \mathrm{~s}^{-2}\right)$ at $80-\mathrm{km}$ neighborhood size for the six WRF microphysics ensembles.

\begin{tabular}{lcc}
\hline \hline \multicolumn{1}{c}{ Ensemble member } & Max SNS & Mean SNS \\
\hline Ensemble 1 (WSM6) & 0.50 & 0.48 \\
Ensemble 2 (WDM6) & 0.57 & 0.51 \\
Ensemble 3 (Thompson) & 0.51 & 0.49 \\
Ensemble 4 (Thompson aerosol-aware) & 0.51 & 0.48 \\
Ensemble 5 (NSSL double-moment 4-ice) & 0.54 & 0.48 \\
Ensemble 6 (Morrison double-moment) & 0.52 & 0.49 \\
\hline
\end{tabular}


a) Ensemble 1 (WSM6)

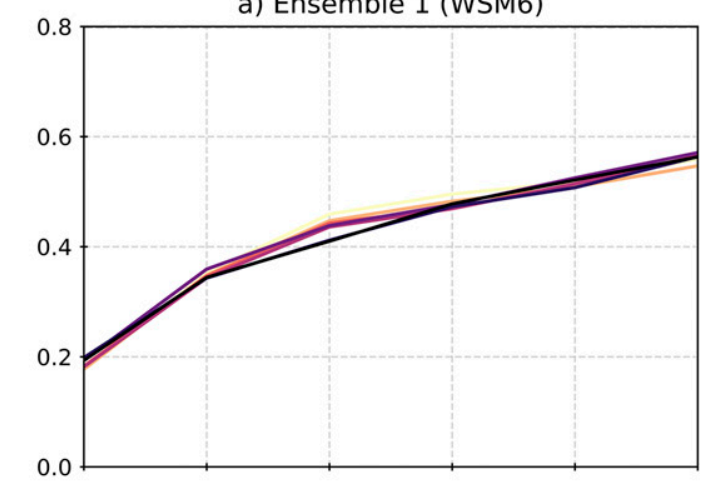

c) Ensemble 3 (Thompson)

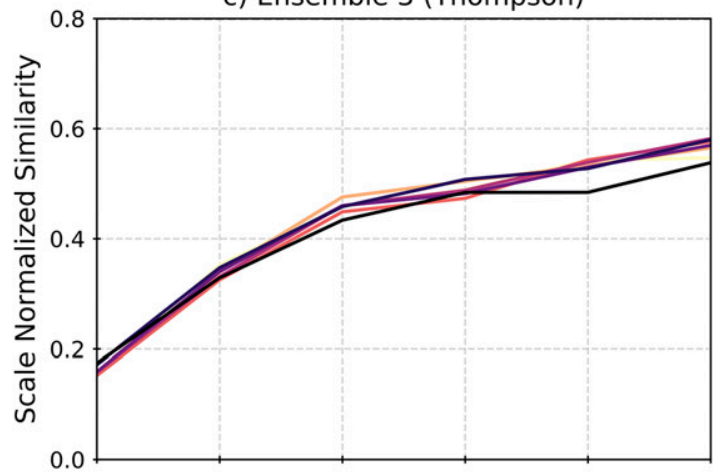

e) Ensemble 5 (NSSL 2M 4-Ice)

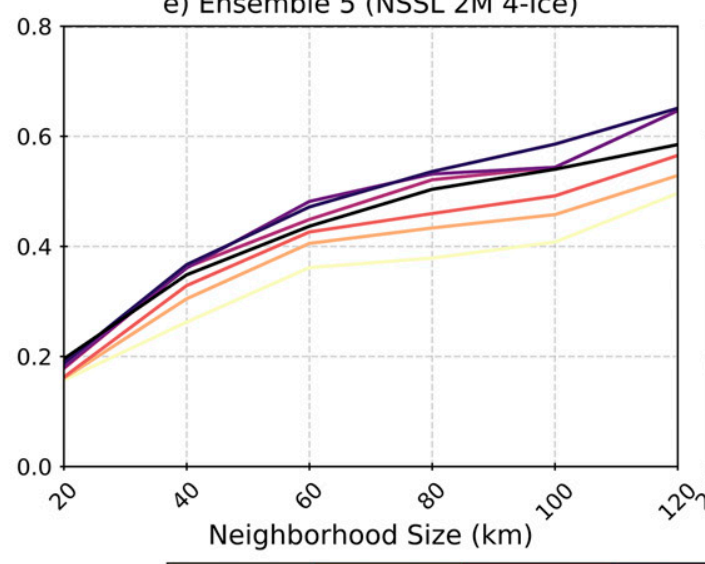

b) Ensemble 2 (WDM6)

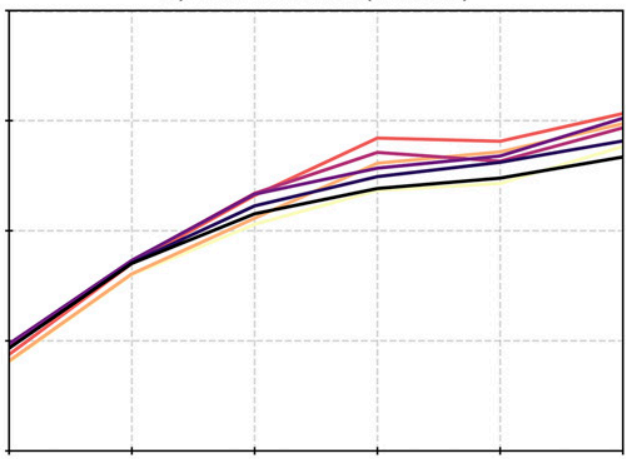

d) Ensemble 4 (Thompson Aerosol-Aware)

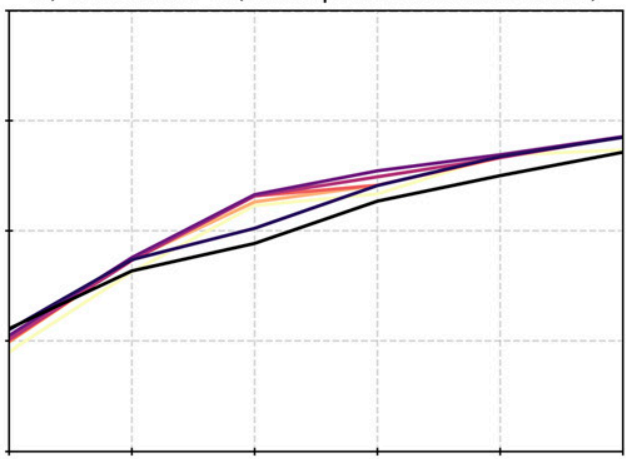

f) Ensemble 6 (Morrison 2M)

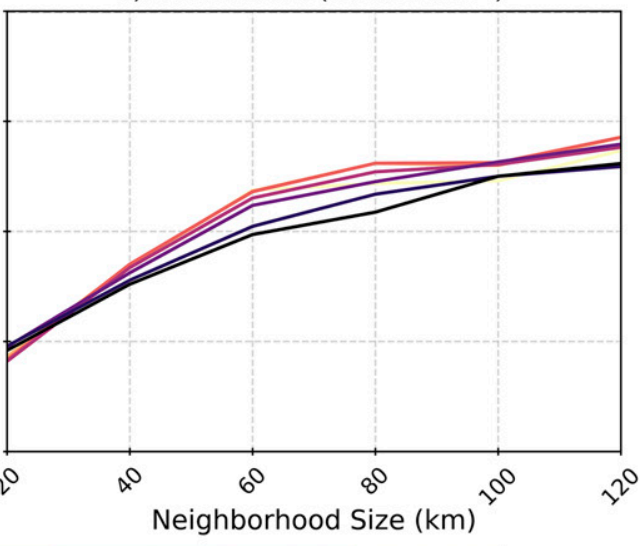

\begin{tabular}{|c|c|c|c|c|c|}
\hline$\vartheta^{0}$ & 9 & $8^{\circ}$ & $\uparrow^{0}$ & $6^{\circ}$ & 50 \\
\hline \multicolumn{6}{|c|}{ UH Threshold $\left(\mathrm{m}^{2} \mathrm{~s}^{-2}\right)$} \\
\hline
\end{tabular}

FIG. 9. Scale-normalized similarity (SNS; Trapp et al. 2011) skill scores as a function of grid spacing for various severe proxy thresholds of the six WRF ensembles. Plot titles indicate the ensemble member microphysics parameterization.

event (>2100 UTC 21 January), particularly once there is ongoing convection over the region of interest.

The identified percent changes to tornadic activity proxy during the first day of the event (0900-2100 UTC 21 January) suggest that SSTs of more distant marine areas (Caribbean Sea) can modulate convective hazard frequency if they are in the path of air parcels being advected toward the event and there is sufficient time for air parcels to move onshore (Table 4, top). These results also suggest that warm northeast GoM SSTs played an important role in the onset severity of the 2123 January 2017 tornado outbreak in addition to other factors (e.g., large-scale environment), and that the first day of the outbreak could have been less severe if the 
TABLE 4. Cumulative hourly tornadic activity proxy for 21-23 Jan (0900-0900 UTC) for the WRF perturbed sea surface temperature (SST) simulations in terms of the percent change relative to the control run. The 15-21 Jan 2017 SSTs were cooled or warmed as indicated across the peak moisture uptake (MU) areas [southeast Gulf of Mexico (GoM) and northwest Caribbean Sea], northeast GoM, and GoM basin. Changes in tornado proxy were also decomposed into 12-h intervals: 0900-2100 UTC 21 Jan, 2100 UTC 21 Jan-0900 UTC 22 Jan, 0900-2100 UTC 22 Jan, and 2100 UTC 22 Jan-0900 UTC 23 Jan.

\begin{tabular}{|c|c|c|c|}
\hline & Degrees & Tornado proxy ( $\pm \%$ change $)$ & Tornado proxy $( \pm \%$ change per $12 \mathrm{~h})$ \\
\hline \multicolumn{4}{|l|}{ Peak MU } \\
\hline SST cooling & $-2^{\circ} \mathrm{C}$ & $+5 \%$ & $-30 \%,+7 \%,+8 \%,+2 \%$ \\
\hline SST cooling & $-1^{\circ} \mathrm{C}$ & $+3 \%$ & $-80 \%,+9 \%,+2 \%,+15 \%$ \\
\hline SST warming & $+1^{\circ} \mathrm{C}$ & $+9 \%$ & $+150 \%,+6 \%,+12 \%,-28 \%$ \\
\hline SST warming & $+2^{\circ} \mathrm{C}$ & $+9 \%$ & $+110 \%,+6 \%,+7 \%,-8 \%$ \\
\hline \multicolumn{4}{|l|}{ NE GoM } \\
\hline SST cooling & $-2^{\circ} \mathrm{C}$ & $+4 \%$ & $-10 \%,+7 \%,+10 \%,-10 \%$ \\
\hline SST cooling & $-1^{\circ} \mathrm{C}$ & $-14 \%$ & $-70 \%,-22 \%,-6 \%,+2 \%$ \\
\hline SST warming & $+1^{\circ} \mathrm{C}$ & $+7 \%$ & $+0 \%,+9 \%,+19 \%,-18 \%$ \\
\hline SST Warming & $+2^{\circ} \mathrm{C}$ & $+11 \%$ & $+70 \%,+7 \%,+18 \%,-10 \%$ \\
\hline \multicolumn{4}{|l|}{ Full GoM } \\
\hline SST cooling & $-2^{\circ} \mathrm{C}$ & $+7 \%$ & $+50 \%,+25 \%,-2 \%,-18 \%$ \\
\hline SST cooling & $-1^{\circ} \mathrm{C}$ & $+5 \%$ & $+20 \%,+12 \%,+2 \%,-10 \%$ \\
\hline SST warming & $+1^{\circ} \mathrm{C}$ & $-8 \%$ & $-10 \%,-11 \%,+2 \%,-25 \%$ \\
\hline SST warming & $+2^{\circ} \mathrm{C}$ & $-9 \%$ & $-50 \%,-17 \%,-5 \%,+10 \%$ \\
\hline
\end{tabular}

northeast GoM was not at record warmth (Table 4, middle). Warmer SSTs imply more moisture available for advection northward that could result in greater convective instability (Molina et al. 2016), which Trapp and Hoogewind (2016) found to result in more intense convection (albeit not proportional). While we did not find substantial MU originating from the northeast GoM, these results suggest that lower magnitude moisture contribution areas can still be influential. Basinwide cooling and warming of GoM temperatures shows a different relationship; cooling of GoM SSTs resulted in more tornadic convection activity during the first day of the outbreak, while warming of GoM SSTs resulted in less tornadic activity (Table 4). This result is also reflected in negative correlation coefficients $(-0.58$ Pearson and -0.83 Spearman's rank) between GoM basin SST perturbations and changes in tornado proxy. These results are surprising because they contain the northeast GoM region, which was found to have a different effect on severe convective activity, suggesting that, at least for this tornado outbreak, the northwest Caribbean Sea played a more influential role as a moisture source. A hypothesis for these nonlinear results will be discussed in the following subsection. Cumulative sums in tornadic thunderstorm proxy were also computed for other UH thresholds (e.g., $\mathrm{UH} \geq 100 \mathrm{~m}^{2} \mathrm{~s}^{-2}$ ) to ensure that results are not solely dependent on the predefined threshold (Fig. 10). All tornadic activity proxies show similar results for the first day of the event (Fig. 10), although the magnitude of percent change does vary between UH thresholds, suggesting some sensitivity to the chosen threshold.

Spatial differences between the tornadic thunderstorm proxy of SST perturbed simulations and the control run were also computed during the first day of the outbreak, with differences smoothed using a two-dimensional 120-km Gaussian smoother to extract the anomaly signal from noise (Fig. 11). Cooling of peak MU areas shows a decrease in tornado proxy activity across Georgia and Mississippi ( $\leq 0 \mathrm{~m}^{2} \mathrm{~s}^{-2}$ smoothed tornado proxy), whereas warming shows an increase across northern Florida, southern Georgia, and southern Alabama $\left(\geq 0 \mathrm{~m}^{2} \mathrm{~s}^{-2}\right.$ smoothed tornado proxy; Figs. 11a-d). Similar to results in Table 4, cooling of the northeast GoM results in decreased tornadic convection activity across the Southeast, while warming results in increased tornadic convection activity across the same region (Figs. 11e-h). In contrast to peak MU and northeast GoM SST perturbations, warming of the GoM basin decreased tornado proxy frequency, while cooling increased proxy frequency (Figs. 11i-1).

The emergence of these tornado proxy anomaly signals when considering the first day of the tornado outbreak suggests that at times storm- and mesoscale processes can modify tornadic proxy activity and obscure upstream SST influences later in an event. Thus, synoptic-scale moisture advection may be more relevant for the prediction of precursor environments of tornadic storms, while mesoscale features could be more relevant once an event is ongoing. While the contribution of lowlevel moisture from marine regions is important to winter convective development (Molina and Allen 2019), it is important to acknowledge that moisture is only one factor in storm development which relies on a complex interplay of various influences (e.g., thermodynamic and kinematic; Doswell et al. 1996). Additionally, the response of severe thunderstorm activity to perturbed SSTs 
a) Peak MU
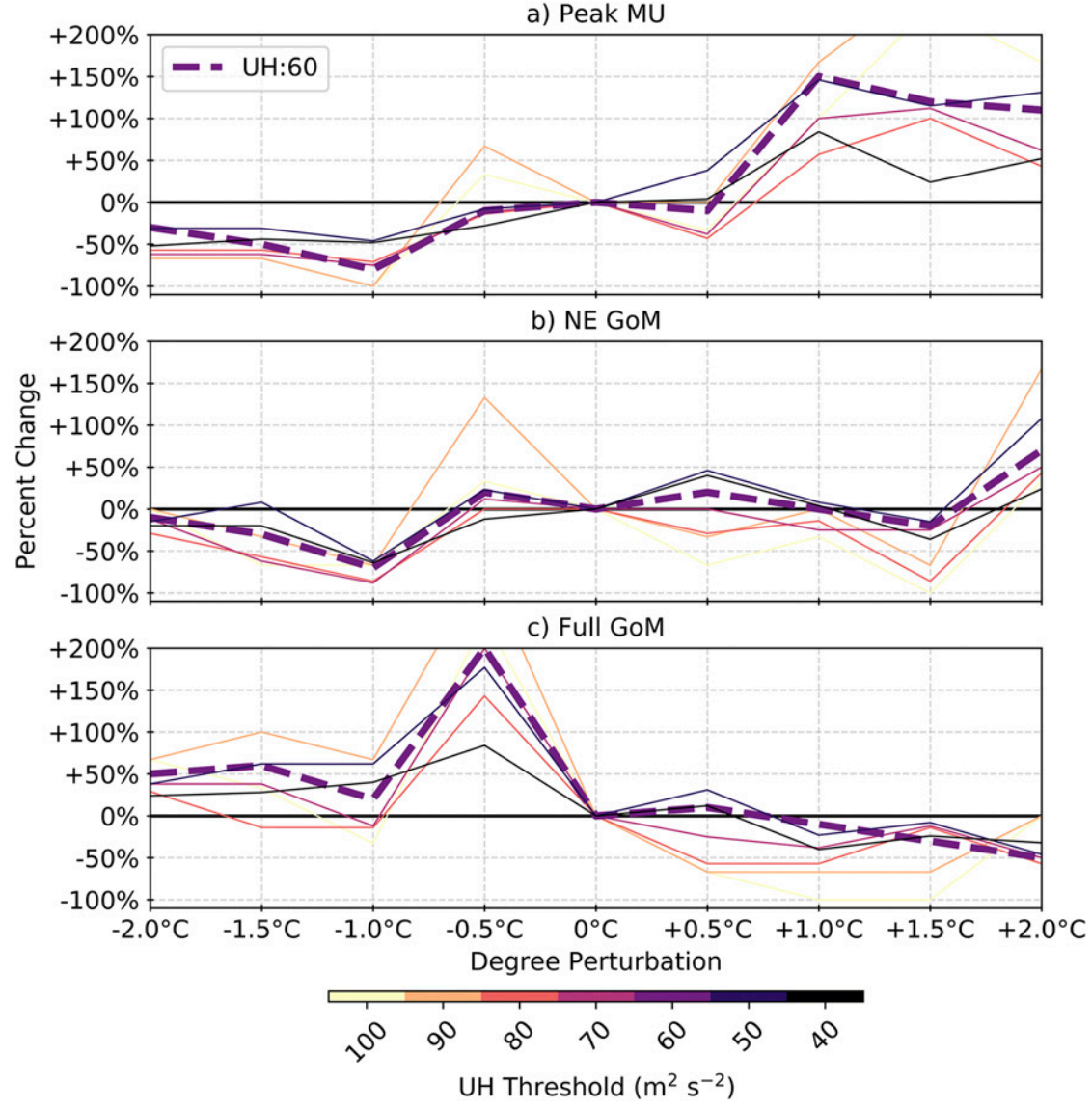

FIG. 10. Percent change in cumulative sum of the tornado proxy during 0900-2100 UTC 21 Jan for (a) peak moisture uptake areas, (b) northeast GoM, and (c) GoM basin. Proxy parameter thresholds as indicated in color bar. The dashed line represents the lowest error proxy combination for the control simulation (as shown in Fig. 9). The black solid line delineates $0 \%$ change in tornado proxy.

may differ when considering events associated with different synoptic-scale patterns and/or events that occurred during other seasons (e.g., spring). Thus, these results are specific to this case study and methodological setup.

\section{f. SST sensitivity analysis: Convective morphology and environments}

Large-scale simulated reflectivity patterns of perturbed SST simulations broadly resemble the spatial coverage of the 21-23 January 2017 tornado outbreak (Fig. 12), given the strong influence of synoptic-scale flow and forcing for large-scale ascent. However, finerscale details related to convective morphology and evolution differ across the perturbed SST simulations (Fig. 12) and could partly explain some of the modulations in tornadic convection proxy identified in the previous subsection. In this subsection, we attempt to trace mesoscale convection changes to modified thermodynamics that stem in part from perturbed SSTs.
A distinct feature of the 21-23 January 2017 tornado outbreak was the complex evolution of a multicellular cluster into a QLCS via upscale growth before 2100 UTC 21 January. The simulations with SSTs cooled by $-1^{\circ}$ and $-2^{\circ} \mathrm{C}$ across peak MU areas (northwest Caribbean Sea and southeast GoM) show that a break occurred between convection over Georgia and the Carolinas (Figs. 12a,b), which differs from the control run (Fig. 12, top left) and radar observations of the event (Fig. 4d). Overall, a more disorganized evolution of the mixed-mode convection and QLCS occurred before 2100 UTC 21 January, with overall weakening of convection apparent (lower dB $Z$ values; Figs. 12a,b). Weaker convection would suggest a reduction in the potential for severe thunderstorm hazards, which supports earlier results that identified a reduction in cumulative tornadic activity proxy when peak MU areas were cooled.

In contrast, warming of peak MU areas by $+1^{\circ} \mathrm{C}$ shows an increase in $\mathrm{dBZ}$ magnitude along the QLCS, 
0900-2100 UTC 21 Jan
a) $-2^{\circ} \mathrm{C}$
b) $-1{ }^{\circ} \mathrm{C}$
c) $+1^{\circ} \mathrm{C}$
d) $+2^{\circ} \mathrm{C}$

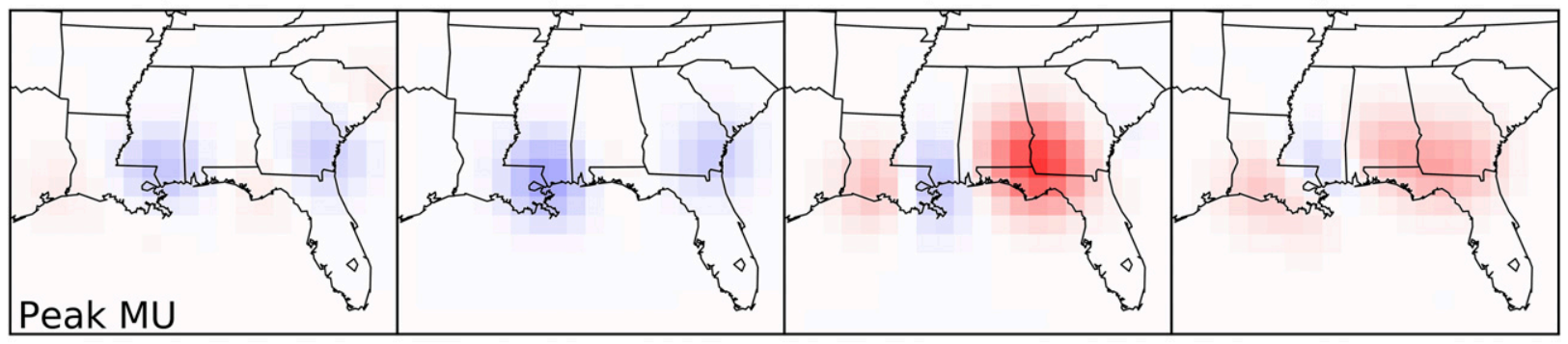

e) $-2^{\circ} \mathrm{C}$

f) $-1^{\circ} \mathrm{C}$

g) $+1^{\circ} \mathrm{C}$

h) $+2{ }^{\circ} \mathrm{C}$

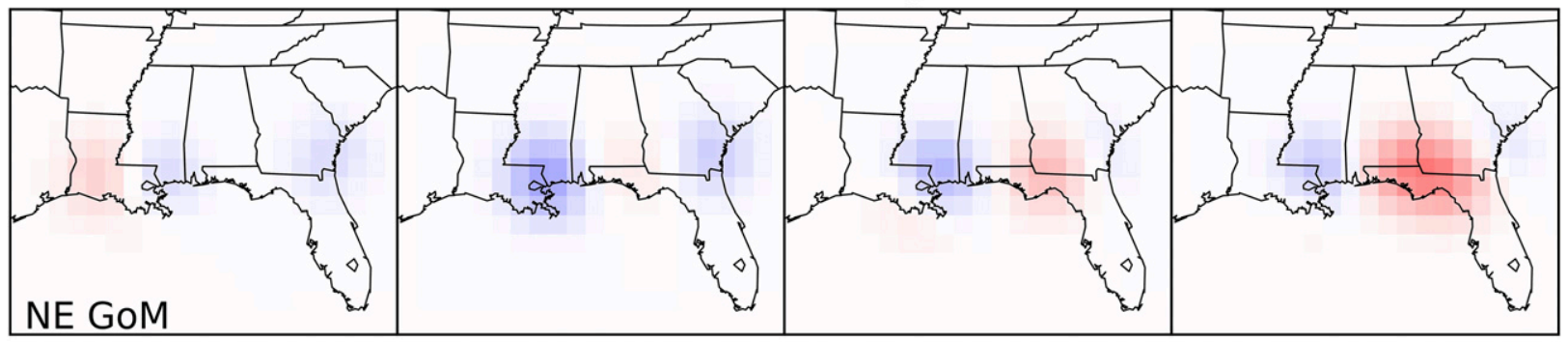

i) $-2^{\circ} \mathrm{C}$

j) $-1^{\circ} \mathrm{C}$

k) $+1^{\circ} \mathrm{C}$

l) $+2^{\circ} \mathrm{C}$
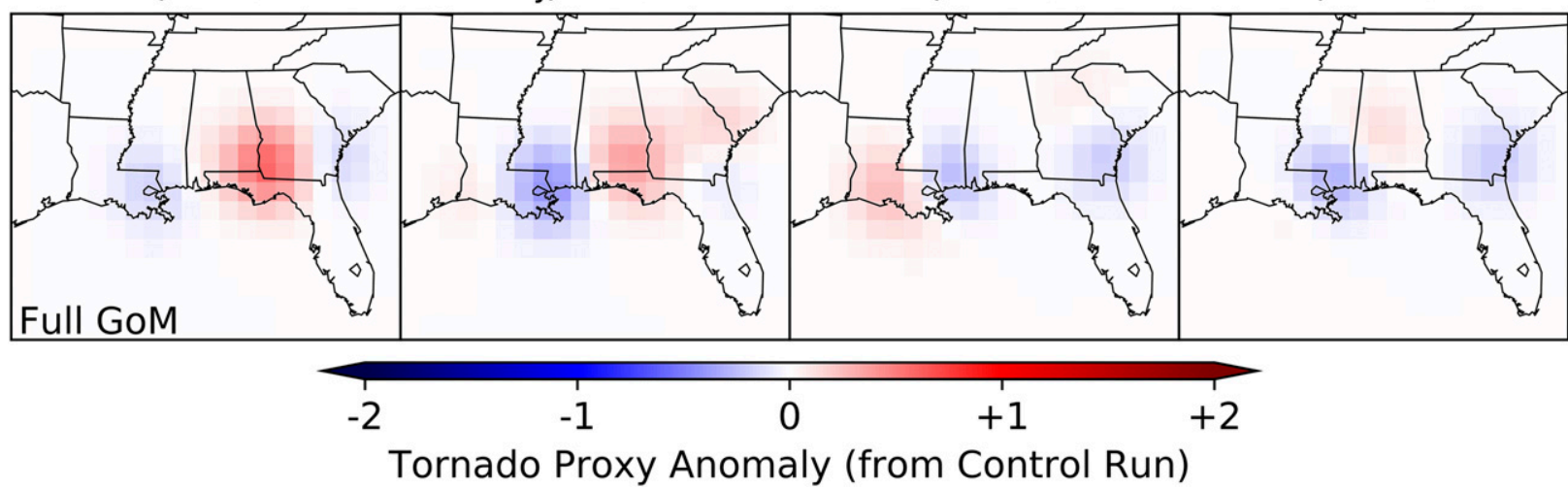

FIG. 11. Tornado proxy anomalies of the perturbed SST simulations for 0900-2100 UTC 21 Jan 2017. Anomalies were gridded onto an $80 \mathrm{~km} \times 80 \mathrm{~km}$ grid and smoothed using a 120-km Gaussian smoother. Perturbed SST regions include (a)-(d) peak moisture uptake areas, (e)-(h) northeast GoM, and (i)-(l) GoM basin.

suggesting an increased likelihood of severe thunderstorm activity from the propagating line of storms (Fig. 12c). Warming of $+2^{\circ} \mathrm{C}$ also shows more intense simulated radar reflectivity, but off the Georgia coastline as opposed to northern Florida (Fig. 12d), which may explain why tornadic thunderstorm proxy anomalies were greater over northern Florida for the $+1^{\circ} \mathrm{C}$ run as compared to the $+2^{\circ} \mathrm{C}$ run (Figs. 11c,d).

SST perturbations of the northeast GoM region resulted in more subtle changes to simulated convective morphology associated with the tornado outbreak, which we speculate could be partly due to the smaller surface area of perturbed SSTs and the region's closer proximity to the Southeast, providing less time for overlying air mass modification (Figs. 12e-h). The QLCS across the four simulations have similar structure, location, and intensity (Figs. 12e-h).

Model radar reflectivity for simulations with GoM basin SSTs perturbed to a warmer state are distinct from the others (Figs. 12i-1). The $+1^{\circ}$ and $+2^{\circ} \mathrm{C}$ simulations resulted in a lower aggregate total of tornadic storm proxy as compared to the control run (Figs. 12k,l), which could be due to an acceleration in forward speed of convection over the Southeast or an overall different convective evolution that influenced 

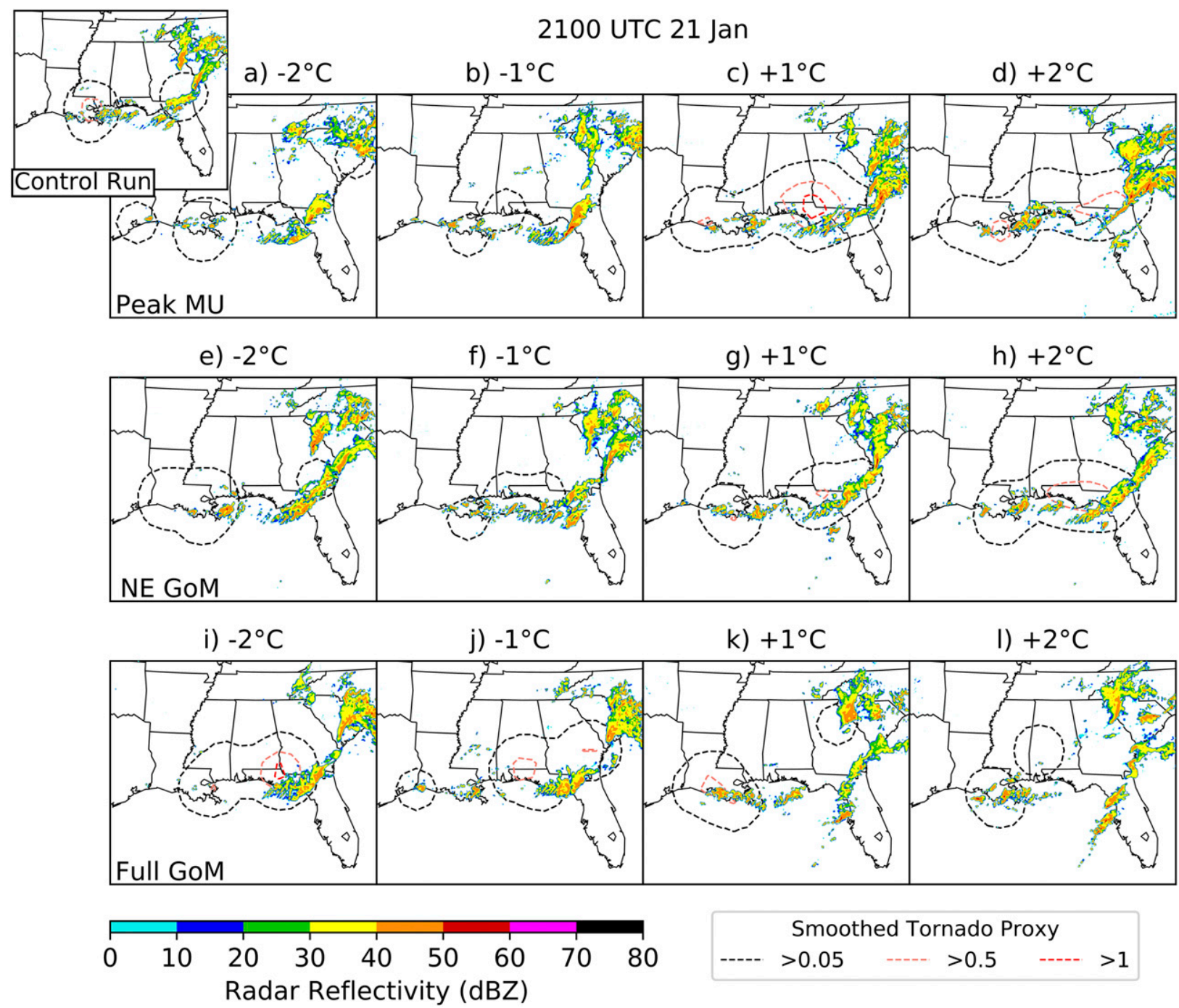

FIG. 12. Simulated 2-km radar reflectivity at 2100 UTC 21 Jan 2017 for the perturbed SST simulations: (a)-(d) peak moisture uptake areas, (e)-(h) northeast GoM, and (i)-(l) GoM basin. Control run simulated 2-km (AGL) radar reflectivity located at the top-left corner for reference. Contour lines show the tornado proxy aggregated from 0900 to 2100 UTC 21 Jan smoothed using an 80-km Gaussian smoother for visualization of associated severe thunderstorm activity.

the subsequent storm locations. Some sensitivity to the magnitude of perturbation is also evident, given that convection is positioned farther east in the warmest simulation as compared to cooler simulations over Florida and the northeast GoM (Figs. 12i-1). A comprehensive understanding of the causal relationships is not yet clear and further study of these types of potential effects may reveal more conclusive evidence.

SST perturbation effects on moisture and thermodynamic variables, such as $2-\mathrm{m}$ dewpoint temperature, were also explored (Fig. 13). Changes to these parameters were physically plausible. Warmer SSTs resulted in more low-level moisture as compared to the WRF control run environment with some sensitivity to the magnitude of the SST perturbation. In contrast, cooler SSTs resulted in less low-level moisture content. However, these modulations were mostly confined to air masses immediately overlying or downstream of the perturbed SST areas (Fig. 13). As air masses were advected over the Southeast, anomaly signals were substantially reduced (but not eliminated) as air parcels likely interacted with cooler land surfaces, extratropical cyclone dynamics, and turbulent fluxes. It is possible that the limited signal over land is unique to this case study and methodological setup, and that other tornado outbreaks may yield different results. Meteorological details resulting from SST perturbations in convection-allowing 


\section{a) $-2^{\circ} \mathrm{C}(\mathrm{b})-1^{\circ} \mathrm{C}$ \\ 0900 UTC 21 Jan}
a) $-2{ }^{\circ} \mathrm{C}$
b) $-1{ }^{\circ} \mathrm{C}$
c) $+1^{\circ} \mathrm{C}$
d) $+2{ }^{\circ} \mathrm{C}$

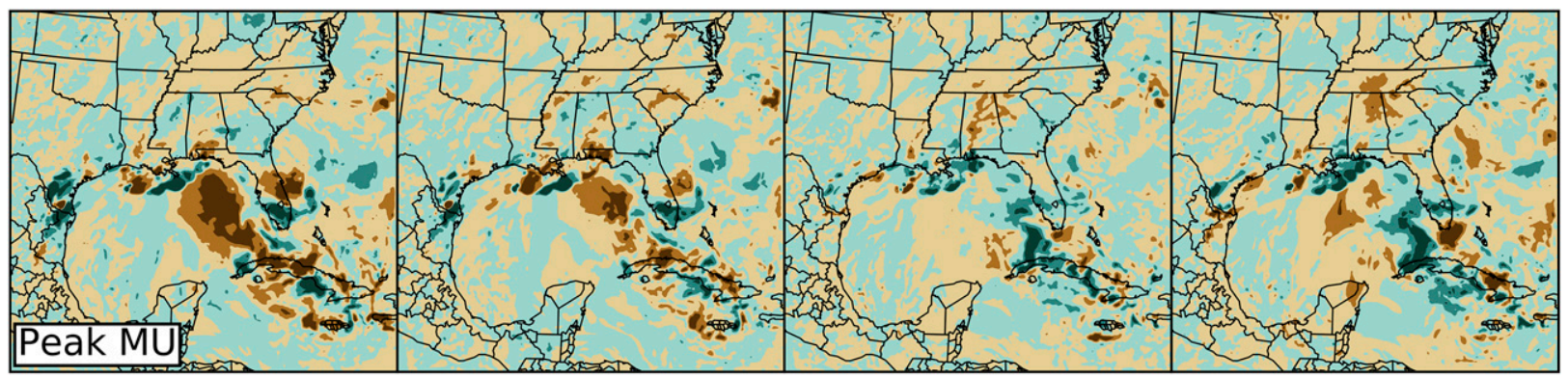
e) $-2{ }^{\circ} \mathrm{C}$
f) $-1{ }^{\circ} \mathrm{C}$
g) $+1^{\circ} \mathrm{C}$
h) $+2{ }^{\circ} \mathrm{C}$
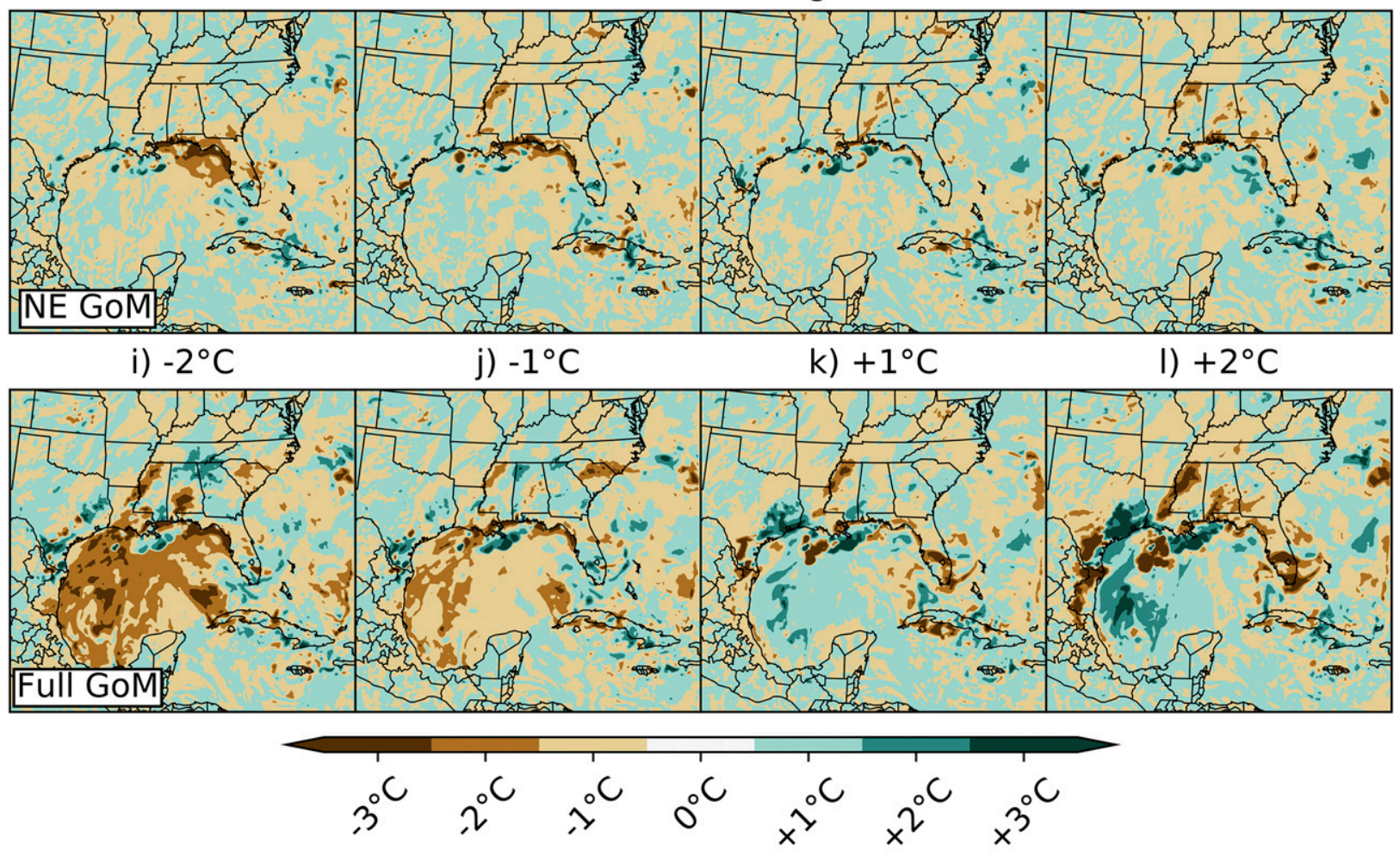

\section{2-m Dew Point Temperature Anomaly $\left({ }^{\circ} \mathrm{C}\right)$}

FIG. 13. 2-m dewpoint temperature $\left({ }^{\circ} \mathrm{C}\right)$ anomalies for the perturbed SST simulations (perturbed runs - control run): (a)-(d) peak moisture uptake areas, (e)-(h) northeast GoM, and (i)-(l) GoM basin. Anomalies shown for 0900 UTC 21 Jan with a 2D Gaussian smoother applied (with a standard deviation of $8 \mathrm{~km}$ ).

model simulations should be further explored in future work.

\section{Conclusions}

Aspects of the 21-23 January 2017 tornado outbreak were analyzed in this research article. The 3-day outbreak consisted of high tornado frequency and coincided with anomalously warm GoM SSTs. Using the NOAA ARL HYSPLIT model and a Lagrangian-based diagnostic, we have shown that moisture contributions to the 21-23 January 2017 tornado outbreak primarily emanated from the southeast GoM and the northwest Caribbean Sea. The warmest surface water temperatures across the northeast GoM did not overlap peak MU, but did coincide with large meridional moisture advection that preceded the tornado outbreak. SSTs across areas of peak MU, the GoM basin, and the record-warm waters of the northeast GoM were subsequently perturbed in various WRF simulations, with model-generated convective storm forecasts compared to a control run. These simulations have shown that 
high-impact convective events are sensitive to upstream SSTs, whether displaced by more than $1000 \mathrm{~km}$ from the CONUS (e.g., Caribbean Sea) or adjacent to the coastline (e.g., northeast GoM). However, in this case, changes were most evident during the first day of the tornado outbreak (before 2100 UTC 21 January), possibly because (i) high moisture content remained in place despite modification of local environments by ongoing convection and/or (ii) ongoing thunderstorms can modify the surrounding environment and contaminate potential boundary layer influences from upstream SST perturbations.

It was also shown that the relationship between SSTs and convection is not linear. Incremental cooling or warming of SSTs did not necessarily result in comparable magnitude changes to the tornadic storm proxy or precursor environments. For example, warming of the GoM basin decreased tornadic activity, yet warming of peak MU areas and the northeast GoM increased tornadic activity. These nonlinearities may be due to the evolution of mesoscale features, such as cold pools, that can result in elevated convection and reduced potential for severe thunderstorm activity. Warmer SSTs may not robustly increase downstream CAPE or 2-m dewpoint temperatures given potential interactions with terrain and/or extratropical dynamics once the air mass is over land. These cross-scale interactions make it difficult to generalize results and the mixed-convective modes further complicate conclusions. A probabilistic framework, considering perturbed model physics and model initial conditions could be used in future work to understand the robustness of the presented results to the model setup and the chaotic nature of the atmosphere. Additionally, SST perturbations for other tornado case studies with different synoptic-scale setups may produce alternative results. Moreover, while this event may be representative of winter Southeast tornadoes, this analysis may not be consistent with tornadoes of the Great Plains or another season (Trapp and Hoogewind 2016). Nevertheless, winter months that experience increases in GoM SSTs have been linked to increases in severe thunderstorm frequency (Molina et al. 2018). Given the overall warming trend of the GoM (Allard et al. 2016) and an eastward shift in peak tornado frequency (Gensini and Brooks 2018), it is important to continue to further explore the contribution of anomalously warm GoM surface waters to hazardous convection in a changing climate (Allen 2018). Results from this case study suggest that continued warming of the GoM $\left(>+2^{\circ} \mathrm{C}\right)$ may not drive linear changes to future winter tornado frequency.

Acknowledgments. This work originates from M. J. Molina's dissertation conducted while enrolled in the Earth and Ecosystem Science Ph.D. program at Central
Michigan University, which provided funding support. Funding was also provided by the National Center for Atmospheric Research (NCAR) Advanced Study Program, which is sponsored by the National Science Foundation. High-performance computing support on Cheyenne (doi:10.5065/D6RX99HX) was provided by the NCAR Computational and Information Systems Laboratory. We offer our gratitude to Dr. Patrick T. Marsh (NOAA Storm Prediction Center) for early provision of 21-23 January 2017 tornado reports and Dr. Cameron R. Homeyer (University of Oklahoma) for provision of GridRad data. We also acknowledge Dr. Vittorio A. Gensini (Northern Illinois University) and Dr. Daria B. Kluver (Central Michigan University) for providing valuable feedback regarding the study's methodology. We thank Craig S. Schwartz (NCAR/MMM) and Dr. Morris L. Weisman (NCAR/MMM) for internally reviewing this article. We are also very grateful for the detailed and constructive feedback provided by three anonymous journal reviewers. The NOAA Air Resources Laboratory provided the HYSPLIT model and NCAR provided WRF. The idealized simulations generated in this study are available upon request from the corresponding author. NARR data in ARL format used in this study is available from the Real-time Environmental Applications and Display sYstem (READY; Rolph et al. 2017) web page at https://www.ready.noaa.gov/archives.php. Other NARR (Mesinger et al. 2006) fields can be obtained from the NOAA/Earth System Research Laboratory at https:// www.esrl.noaa.gov/psd/data/gridded/data.narr.html. NOAA Optimum Interpolation SST data can be downloaded from https://www.ncdc.noaa.gov/oisst/data-access. SPC tornado reports can be obtained from https://www. spc.noaa.gov/wcm/index.html\#data. The SPC Mesoanalysis system can be found at https://www.spc.noaa.gov/exper/ ma_archive/.

\section{REFERENCES}

Allard, J., J. V. Clarke III, and B. D. Keim, 2016: Spatial and temporal patterns of in situ sea surface temperatures within the Gulf of Mexico from 1901-2010. Amer. J. Climate Change, 5, 314-343, https://doi.org/10.4236/ajcc.2016.53025.

Allen, J. T., 2018: Climate change and severe thunderstorms. Oxford Research Encyclopedia of Climate Science, Oxford University Press, https://doi.org/10.1093/acrefore/9780190228620.013.62.

Ancell, B. C., A. Bogusz, M. J. Lauridsen, and C. J. Nauert, 2018: Seeding chaos: The dire consequences of numerical noise in NWP perturbation experiments. Bull. Amer. Meteor. Soc., 99, 615-628, https://doi.org/10.1175/BAMS-D-17-0129.1.

Angevine, W. M., and K. Mitchell, 2001: Evaluation of the NCEP mesoscale Eta model convective boundary layer for air quality applications. Mon. Wea. Rev., 129, 2761-2775, https://doi.org/ 10.1175/1520-0493(2001)129<2761:EOTNME>2.0.CO;2.

Ashley, W. S., and S. M. Strader, 2016: Recipe for disaster: How the dynamic ingredients of risk and exposure are changing the 
tornado disaster landscape. Bull. Amer. Meteor. Soc., 97, 767-786, https://doi.org/10.1175/BAMS-D-15-00150.1.

—, A. J. Krmenec, and R. Schwantes, 2008: Vulnerability due to nocturnal tornadoes. Wea. Forecasting, 23, 795-807, https:// doi.org/10.1175/2008WAF2222132.1.

Baldini, L. M., F. McDermott, J. U. Baldini, M. J. Fischer, and M. Möllhoff, 2010: An investigation of the controls on Irish precipitation $\delta^{18} \mathrm{O}$ values on monthly and event timescales. Climate Dyn., 35, 977-993, https://doi.org/10.1007/s00382-010-0774-6.

Barnes, S., and C. Newton, 1986: Thunderstorms in the synoptic setting. Thunderstorm Morphology and Dynamics, 2nd ed. E. Kessler, Ed., University of Oklahoma Press, 75-112.

Bekiashev, K. A., and V. V. Serebriakov, Eds., 1981: International Hydrographic Organization (IHO). International Marine Organizations: Essays on Structure and Activities, Springer, 478-485.

Benjamin, S. G., and Coauthors, 2016: A North American hourly assimilation and model forecast cycle: The Rapid Refresh. Mon. Wea. Rev., 144, 1669-1694, https://doi.org/10.1175/ MWR-D-15-0242.1.

Blumberg, W. G., K. T. Halbert, T. A. Supinie, P. T. Marsh, R. L. Thompson, and J. A. Hart, 2017: SHARPpy: An open-source sounding analysis toolkit for the atmospheric sciences. Bull. Amer. Meteor. Soc., 98, 1625-1636, https://doi.org/10.1175/ BAMS-D-15-00309.1.

Bothwell, P. D., J. A. Hart, and R. L. Thompson, 2002: An integrated three-dimensional objective analysis scheme in use at the Storm Prediction Center. 21st Conf. on Severe Local Storms, San Antonio, TX, Amer. Meteor. Soc., JP3.1, http://ams.confex.com/ ams/SLS_WAF_NWP/techprogram/paper_47482.htm.

Bowman, K. P., and C. R. Homeyer, 2017: GridRad-Threedimensional gridded NEXRAD WSR-88D radar data. Research Data Archive at the National Center for Atmospheric Research, Computational and Information Systems Laboratory, accessed March 2019, https://doi.org/10.5065/D6NK3CR7.

Brooks, H. E., 2013: Severe thunderstorms and climate change. Atmos. Res., 123, 129-138, https://doi.org/10.1016/j.atmosres.2012.04.002.

- C. A. Doswell III, and M. P. Kay, 2003: Climatological estimates of local daily tornado probability for the United States. Wea. Forecasting, 18, 626-640, https://doi.org/10.1175/15200434(2003)018<0626:CEOLDT > 2.0.CO;2.

Bryan, G. H., J. C. Wyngaard, and J. M. Fritsch, 2003: Resolution requirements for the simulation of deep moist convection. Mon. Wea. Rev., 131, 2394-2416, https://doi.org/10.1175/15200493(2003)131<2394:RRFTSO > 2.0.CO;2.

Burk, S. D., and W. T. Thompson, 1992: Airmass modification over the Gulf of Mexico: Mesoscale model and airmass transformation model forecasts. J. Appl. Meteor., 31, 925-937, https://doi.org/ 10.1175/1520-0450(1992)031<0925:AMOTGO>2.0.CO;2.

Childs, S. J., R. S. Schumacher, and J. T. Allen, 2018: Coldseason tornadoes: Climatological and meteorological insights. Wea. Forecasting, 33, 671-691, https://doi.org/10.1175/ WAF-D-17-0120.1.

Clark, A. J., J. Gao, P. T. Marsh, T. Smith, J. S. Kain, J. Correia Jr., M. Xue, and F. Kong, 2013: Tornado pathlength forecasts from 2010 to 2011 using ensemble updraft helicity. Wea. Forecasting, 28, 387-407, https://doi.org/10.1175/WAFD-12-00038.1.

Cohen, A. E., S. M. Cavallo, M. C. Coniglio, and H. E. Brooks, 2015: A review of planetary boundary layer parameterization schemes and their sensitivity in simulating southeastern U.S. cold season severe weather environments. Wea. Forecasting, 30, 591-612, https://doi.org/10.1175/WAF-D-14-00105.1.
,,,---- , and I. L. Jirak, 2017: Evaluation of multiple planetary boundary layer parameterization schemes in southeast U.S. cold season severe thunderstorm environments. Wea. Forecasting, 32, 1857-1884, https://doi.org/ 10.1175/WAF-D-16-0193.1.

Cook, A. R., L. M. Leslie, D. B. Parsons, and J. T. Schaefer, 2017: The impact of the El Niño-Southern Oscillation (ENSO) on winter and early spring U.S. tornado outbreaks. J. Appl. Meteor. Climatol., 56, 2455-2478, https://doi.org/10.1175/ JAMC-D-16-0249.1.

Diffenbaugh, N. S., R. J. Trapp, and H. Brooks, 2008: Does global warming influence tornado activity? Eos, Trans. Amer. Geophys. Union, 89, 553-554, https://doi.org/10.1029/2008EO530001.

Done, J., C. A. Davis, and M. Weisman, 2004: The next generation of NWP: Explicit forecasts of convection using the Weather Research and Forecasting (WRF) model. Atmos. Sci. Lett., 5 , 110-117, https://doi.org/10.1002/asl.72.

Doswell, C. A., and L. F. Bosart, 2001: Extratropical synoptic-scale processes and severe convection. Severe Convective Storms, C. A. Doswell, Ed., Springer, 27-69, https://doi.org/10.1007/ 978-1-935704-06-5_2.

— H. E. Brooks, and R. A. Maddox, 1996: Flash flood forecasting: An ingredients-based methodology. Wea. Forecasting, 11, 560-581, https://doi.org/10.1175/1520-0434(1996)011<0560: FFFAIB $>2.0 . \mathrm{CO} ; 2$.

Draxler, R. R., and G. Hess, 1997: Description of the HYSPLIT_4 modeling system. NOAA Tech. Memo. ERL ARL-224, NOAA/Air Resources Laboratory, $24 \mathrm{pp}$.

Ebert, E. E., 2008: Fuzzy verification of high-resolution gridded forecasts: A review and proposed framework. Meteor. Appl., 15, 51-64, https://doi.org/10.1002/MET.25.

Edwards, R., and S. J. Weiss, 1996: Comparisons between Gulf of Mexico sea surface temperature anomalies and southern U.S. severe thunderstorm frequency in the cool season. Preprints, 18th Conf. on Severe Local Storms, San Francisco, CA, Amer. Meteor. Soc., 317-320.

— J. G. LaDue, J. T. Ferree, K. Scharfenberg, C. Maier, and W. L. Coulbourne, 2013: Tornado intensity estimation: Past, present, and future. Bull. Amer. Meteor. Soc., 94, 641-653, https://doi.org/10.1175/BAMS-D-11-00006.1.

Erlingis, J. M., J. J. Gourley, and J. B. Basara, 2019: Diagnosing moisture sources for flash floods in the United States Part I: Kinematic trajectories. J. Hydrometeor., 20, 1495-1509, https:// doi.org/10.1175/JHM-D-18-0119.1.

Evans, J. S., and J. L. Guyer, 2006: The relationship of cool season significant tornado events and buoy data in the western Gulf of Mexico. 23rd Conf. on Severe Local Storms, St. Louis, MO, Amer. Meteor. Soc., P3.1, https://ams.confex.com/ams/23SLS/ techprogram/paper_115444.htm.

Fujita, T. T., 1971: Proposed characterization of tornadoes and hurricanes by area and intensity. University of Chicago SMRP Research Paper 91, 42 pp.

Gallo, B. T., A. J. Clark, and S. R. Dembek, 2016: Forecasting tornadoes using convection-permitting ensembles. Wea. Forecasting, 31, 273-295, https://doi.org/10.1175/WAF-D15-0134.1.

Gensini, V. A., and T. L. Mote, 2014: Estimations of hazardous convective weather in the United States using dynamical downscaling. J. Climate, 27, 6581-6589, https://doi.org/10.1175/ JCLI-D-13-00777.1.

, and H. E. Brooks, 2018: Spatial trends in United States tornado frequency. npj Climate Atmos. Sci., 1, 38, https://doi.org/ 10.1038/s41612-018-0048-2. 
— T. L. Mote, and H. E. Brooks, 2014: Severe-thunderstorm reanalysis environments and collocated radiosonde observations. J. Appl. Meteor. Climatol., 53, 742-751, https://doi.org/ 10.1175/JAMC-D-13-0263.1.

Gustafsson, M., D. Rayner, and D. Chen, 2010: Extreme rainfall events in southern Sweden: Where does the moisture come from? Tellus, 62A, 605-616, https://doi.org/10.1111/j.16000870.2010.00456.x.

Guyer, J. L., A. K. Kis, K. N. Venable, and D. A. Imy, 2006: Cool season significant (F2-F5) tornadoes in the Gulf Coast states. 23rd Conf. on Severe Local Storms, St. Louis, MO, Amer. Meteor. Soc., 4.2, https://ams.confex.com/ams/23SLS/techprogram/paper_ 115320.htm.

Hart, J., and W. Korotky, 1991: The SHARP workstation v1. 50 users guide. NOAA/National Weather Service, $30 \mathrm{pp}$.

He, J., N. C. Johnson, G. A. Vecchi, B. Kirtman, A. T. Wittenberg, and S. Sturm, 2018: Precipitation sensitivity to local variations in tropical sea surface temperature. J. Climate, 31, 9225-9238, https://doi.org/10.1175/JCLI-D-18-0262.1.

Herring, S. C., N. Christidis, A. Hoell, J. P. Kossin, C. J. Schreck III, and P. A. Stott, 2018: Explaining extreme events of 2016 from a climate perspective. Bull. Amer. Meteor. Soc., 99, S1-S6, https://doi.org/10.1175/BAMS-D-17-0284.1.

Hoerling, M. P., and X. Quan, 2016: How climate change affected US impacts of the 2015-16 El Niño. 2016 Fall Meeting, San Francisco, CA, Amer. Geophys. Union, Abstract A41L-07.

Homeyer, C. R., and K. P. Bowman, 2017: Algorithm description document for version 3.1 of the three-dimensional gridded NEXRAD WSR-88D radar (GridRad) dataset. University of Oklahoma/Texas A\&M University, 23 pp., http://gridrad.org/ pdf/GridRad-v3.1-Algorithm-Description.pdf.

Hong, S.-Y., and J.-O. J. Lim, 2006: The WRF single-moment 6class microphysics scheme (WSM6). J. Korean Meteor. Soc., 42, 129-151.

_- Y. Noh, and J. Dudhia, 2006: A new vertical diffusion package with an explicit treatment of entrainment processes. Mon. Wea. Rev., 134, 2318-2341, https://doi.org/10.1175/ MWR3199.1.

— , K.-S. S. Lim, Y.-H. Lee, J.-C. Ha, H.-W. Kim, S.-J. Ham, and J. Dudhia, 2010: Evaluation of the WRF double-moment 6-class microphysics scheme for precipitating convection. Adv. Meteor., 2010, 707253, https://doi.org/10.1155/2010/707253.

Hoogewind, K. A., M. E. Baldwin, and R. J. Trapp, 2017: The impact of climate change on hazardous convective weather in the United States: Insight from high-resolution dynamical downscaling. J. Climate, 30, 10 081-10100, https://doi.org/ 10.1175/JCLI-D-16-0885.1.

Janish, P. R., and S. W. Lyons, 1992: NGM performance during cold-air outbreaks and periods of return flow over the Gulf of Mexico with emphasis on moisture-field evolution. J. Appl. Meteor., 31, 995-1017, https://doi.org/10.1175/1520-0450(1992) 031<0995:NPDCAO > 2.0.CO;2.

Janjić, Z., 1996: The Mellor-Yamada level-2.5 scheme in the NCEP Eta model. Preprints, 11th Conf. on Numerical Weather Prediction, Norfolk, VA, Amer. Meteor. Soc., 333-334.

Jiménez, P. A., J. Dudhia, J. F. González-Rouco, J. Navarro, J. P. Montávez, and E. García-Bustamante, 2012: A revised scheme for the WRF surface layer formulation. Mon. Wea. Rev., 140, 898-918, https://doi.org/10.1175/MWR-D-11-00056.1.

Jones, T. A., K. M. McGrath, and J. T. Snow, 2004: Association between NSSL mesocyclone detection algorithm-detected vortices and tornadoes. Wea. Forecasting, 19, 872-890, https://doi.org/ 10.1175/1520-0434(2004)019<0872:ABNMDA>2.0.CO;2.
Jung, E., and B. P. Kirtman, 2016: Can we predict seasonal changes in high impact weather in the United States? Environ. Res. Lett., 11, 074018, https://doi.org/10.1088/1748-9326/11/7/074018.

Kain, J. S., S. J. Weiss, J. J. Levit, M. E. Baldwin, and D. R. Bright, 2006: Examination of convection-allowing configurations of the WRF Model for the prediction of severe convective weather: The SPC/NSSL Spring Program 2004. Wea. Forecasting, 21, 167-181, https://doi.org/10.1175/WAF906.1.

_ ing horizontal resolution in the first generation of operational convection-allowing NWP. Wea. Forecasting, 23, 931-952, https://doi.org/10.1175/WAF2007106.1.

King, J. R., M. D. Parker, K. D. Sherburn, and G. M. Lackmann, 2017: Rapid evolution of cool season, low-CAPE severe thunderstorm environments. Wea. Forecasting, 32, 763-779, https://doi.org/10.1175/WAF-D-16-0141.1.

Kis, A. K., and J. M. Straka, 2010: Nocturnal tornado climatology. Wea. Forecasting, 25, 545-561, https://doi.org/10.1175/ 2009WAF2222294.1.

Krocak, M. J., and H. E. Brooks, 2018: Climatological estimates of hourly tornado probability for the United States. Wea. Forecasting, 33, 59-69, https://doi.org/10.1175/WAF-D-17-0123.1.

Läderach, A., and H. Sodemann, 2016: A revised picture of the atmospheric moisture residence time. Geophys. Res. Lett., $\mathbf{4 3}$ 924-933, https://doi.org/10.1002/2015GL067449.

Lakshmivarahan, S., J. M. Lewis, and R. Jabrzemski, Eds., 2017: The Gulf of Mexico problem: Return flow analysis. Forecast Error Correction Using Dynamic Data Assimilation, Springer, 149-205.

Lanicci, J. M., and T. T. Warner, 1997: A case study of lid evolution using analyses of observational data and a numerical model simulation. Wea. Forecasting, 12, 228-252, https://doi.org/ 10.1175/1520-0434(1997)012<0228:ACSOLE > 2.0.CO;2.

Lewis, J. M., and C. A. Crisp, 1992: Return flow in the Gulf of Mexico. Part II: Variability in return-flow thermodynamics inferred from trajectories over the Gulf. J. Appl. Meteor., 31, 882-898, https://doi.org/10.1175/1520-0450(1992)031<0882: RFITGO $>2.0 . \mathrm{CO} ; 2$

—_, C. Hayden, R. Merrill, and J. Schneider, 1989: GUFMEX: A study of return flow in the Gulf of Mexico. Bull. Amer. Meteor. Soc., 70, 24-29, https://doi.org/10.1175/1520-0477(1989) $070<0024$ :GASORF $>2.0 . \mathrm{CO} ; 2$.

_- S. Lakshmivarahan, J. Hu, R. Edwards, R. A. Maddox, R. L. Thompson, and S. F. Corfidi, 2016: Ensemble forecasting of return flow over the Gulf of Mexico. Electron. J. Severe Storms Meteor., 11 (4), http://www.ejssm.org/ojs/index.php/ ejssm/article/viewArticle/155.

Liu, C., and Coauthors, 2017: Continental-scale convectionpermitting modeling of the current and future climate of North America. Climate Dyn., 49, 71-95, https://doi.org/ 10.1007/s00382-016-3327-9.

Mailhot, J., 1992: Numerical simulation of airmass transformation over the Gulf of Mexico. J. Appl. Meteor., 31, 946-963, https://doi.org/ 10.1175/1520-0450(1992)031<0946:NSOATO > 2.0.CO;2.

Mansell, E. R., C. L. Ziegler, and E. C. Bruning, 2010: Simulated electrification of a small thunderstorm with two-moment bulk microphysics. J. Atmos. Sci., 67, 171-194, https://doi.org/ 10.1175/2009JAS2965.1.

May, D. A., M. M. Parmeter, D. S. Olszewski, and B. D. McKenzie, 1998: Operational processing of satellite sea surface temperature retrievals at the Naval Oceanographic Office. Bull. Amer. Meteor. Soc., 79, 397-407, https://doi.org/10.1175/15200477(1998)079<0397:OPOSSS > 2.0.CO;2. 
Mesinger, F., and Coauthors, 2006: North American Regional Reanalysis. Bull. Amer. Meteor. Soc., 87, 343-360, https:// doi.org/10.1175/BAMS-87-3-343.

Miglietta, M. M., J. Mazon, V. Motola, and A. Pasini, 2017: Effect of a positive sea surface temperature anomaly on a Mediterranean tornadic supercell. Sci. Rep., 7, 12828, https://oi.org/10.1038/ s41598-017-13170-0.

Mlawer, E. J., S. J. Taubman, P. D. Brown, M. J. Iacono, and S. A. Clough, 1997: Radiative transfer for inhomogeneous atmospheres: RRTM, a validated correlated-k model for the longwave.J. Geophys. Res., 102,16 663-16682, https://doi.org/ 10.1029/97JD00237.

Molina, M. J., R. Timmer, and J. Allen, 2016: Importance of the Gulf of Mexico as a climate driver for US severe thunderstorm activity. Geophys. Res. Lett., 43, 12 295-12 304, https://doi.org/ 10.1002/2016GL071603.

— thunderstorms. J. Climate, 32, 4321-4346, https://doi.org/ 10.1175/JCLI-D-18-0784.1.

$\longrightarrow$, and — 2020: Regionally-stratified tornadoes: Moisture source physical reasoning and climate trends. Wea. Climate Extremes, 28, 100244, https://doi.org/10.1016/J.WACE.2020.100244.

— _ , and V. A. Gensini, 2018: The Gulf of Mexico and ENSO influence on subseasonal and seasonal CONUS winter tornado variability. J. Appl. Meteor. Climatol., 57, 2439-2463, https://doi.org/10.1175/JAMC-D-18-0046.1.

Molinari, R. L., 1987: Air mass modification over the eastern Gulf of Mexico as a function of surface wind fields and Loop Current position. Mon. Wea. Rev., 115, 646-652, https://doi.org/10.1175/ 1520-0493(1987)115<0646:AMMOTE $>2.0 . C O ; 2$.

Morrison, H., G. Thompson, and V. Tatarskii, 2009: Impact of cloud microphysics on the development of trailing stratiform precipitation in a simulated squall line: Comparison of oneand two-moment schemes. Mon. Wea. Rev., 137, 991-1007, https://doi.org/10.1175/2008MWR2556.1.

Murphy, A. H., and E. S. Epstein, 1989: Skill scores and correlation coefficients in model verification. Mon. Wea. Rev., 117, 572-582, https://doi.org/10.1175/1520-0493(1989)117<0572 SSACCI $>2.0 . \mathrm{CO} ; 2$.

Pfahl, S., E. Madonna, M. Boettcher, H. Joos, and H. Wernli, 2014: Warm conveyor belts in the ERA-Interim dataset (1979-2010) Part II: Moisture origin and relevance for precipitation. J. Climate, 27, 27-40, https://doi.org/10.1175/JCLI-D-13-00223.1.

Potter, S., 2007: Fine-Tuning Fujita: After 35 years, a new scale for rating tornadoes takes effect. Weatherwise, 60, 64-71, https:// doi.org/10.3200/WEWI.60.2.64-71.

Prein, A. F., and Coauthors, 2015: A review on regional convectionpermitting climate modeling: Demonstrations, prospects, and challenges. Rev. Geophys., 53, 323-361, https://doi.org/10.1002/ 2014RG000475.

— , C. Liu, K. Ikeda, R. Bullock, R. M. Rasmussen, G. J. Holland, and M. Clark, 2017a: Simulating North American mesoscale convective systems with a convection-permitting climate model. Climate Dyn., https://doi.org/10.1007/s00382017-3993-2, in press

- R. M. Rasmussen, K. Ikeda, C. Liu, M. P. Clark, and G. J. Holland, 2017b: The future intensification of hourly precipitation extremes. Nat. Climate Change, 7, 48-52, https://doi.org/ 10.1038/nclimate3168.

Reynolds, R. W., T. M. Smith, C. Liu, D. B. Chelton, K. S. Casey, and M. G. Schlax, 2007: Daily high-resolution-blended analyses for sea surface temperature. J. Climate, 20, 5473-5496, https://doi.org/10.1175/2007JCLI1824.1.
Roberts, N. M., and H. W. Lean, 2008: Scale-selective verification of rainfall accumulations from high-resolution forecasts of convective events. Mon. Wea. Rev., 136, 78-97, https://doi.org/ 10.1175/2007MWR2123.1.

Robinson, E. D., R. J. Trapp, and M. E. Baldwin, 2013: The geospatial and temporal distributions of severe thunderstorms from highresolution dynamical downscaling. J. Appl. Meteor. Climatol., 52, 2147-2161, https://doi.org/10.1175/JAMC-D-12-0131.1.

Rolph, G., A. Stein, and B. Stunder, 2017: Real-time environmental applications and display system: READY. Environ. Modell. Software, 95, 210-228, https://doi.org/10.1016/j.envsoft. 2017.06.025.

Schaefer, J. T., and R. Edwards, 1999: The SPC tornado/severe thunderstorm database. Preprints, 11th Conf. on Applied Climatology, Dallas, TX, Amer. Meteor. Soc., 215-220.

Schmid, P., and D. Niyogi, 2012: A method for estimating planetary boundary layer heights and its application over the ARM Southern Great Plains site. J. Atmos. Oceanic Technol., 29, 316-322, https://doi.org/10.1175/JTECH-D-11-00118.1.

Schwartz, C. S., and R. A. Sobash, 2017: Generating probabilistic forecasts from convection-allowing ensembles using neighborhood approaches: A review and recommendations. Mon. Wea. Rev., 145, 3397-3418, https://doi.org/10.1175/MWR-D-16-0400.1.

Sherburn, K. D., and M. D. Parker, 2014: Climatology and ingredients of significant severe convection in high-shear, lowCAPE environments. Wea. Forecasting, 29, 854-877, https:// doi.org/10.1175/WAF-D-13-00041.1.

Skamarock, W. C., and J. B. Klemp, 2008: A time-split nonhydrostatic atmospheric model for weather research and forecasting applications. J. Comput. Phys., 227, 3465-3485, https://doi.org/10.1016/j.jcp.2007.01.037.

Smith, A. B., and J. L. Matthews, 2015: Quantifying uncertainty and variable sensitivity within the US billion-dollar weather and climate disaster cost estimates. Nat. Hazards, 77, 1829-1851, https://doi.org/10.1007/s11069-015-1678-x.

Sobash, R. A., C. S. Schwartz, G. S. Romine, K. R. Fossell, and M. L. Weisman, 2016: Severe weather prediction using storm surrogates from an ensemble forecasting system. Wea. Forecasting, 31, 255-271, https://doi.org/10.1175/WAF-D-15-0138.1.

,,,--- and -2019 : Next-day prediction of tornadoes using convection-allowing models with $1-\mathrm{km}$ horizontal grid spacing. Wea. Forecasting, 34, 1117-1135, https://doi.org/10.1175/ WAF-D-19-0044.1.

Sodemann, H., C. Schwierz, and H. Wernli, 2008: Interannual variability of Greenland winter precipitation sources: Lagrangian moisture diagnostic and North Atlantic Oscillation influence. J. Geophys. Res., 113, D03107, https://doi.org/10.1029/ 2007JD008503

Stein, A., R. R. Draxler, G. D. Rolph, B. J. Stunder, M. Cohen, and F. Ngan, 2015: NOAA's HYSPLIT atmospheric transport and dispersion modeling system. Bull. Amer. Meteor. Soc., 96, 2059-2077, https://doi.org/10.1175/BAMS-D-14-00110.1.

Stohl, A., 1998: Computation, accuracy and applications of trajectories-A review and bibliography. Atmos. Environ., 32, 947-966, https://doi.org/10.1016/S1352-2310(97)00457-3.

Stott, P. A., and Coauthors, 2016: Attribution of extreme weather and climate-related events. Wiley Interdiscip. Rev.: Climate Change, 7, 23-41, https://doi.org/10.1002/WCC.380.

Tewari, M., and Coauthors, 2004: Implementation and verification of the unified NOAH land surface model in the WRF model. 20th Conf. on Weather Analysis and Forecasting/16th Conf. on Numerical Weather Prediction, Seattle, WA, Amer. Meteor. Soc., 2165-2170. 
Thompson, G., and T. Eidhammer, 2014: A study of aerosol impacts on clouds and precipitation development in a large winter cyclone. J. Atmos. Sci., 71, 3636-3658, https://doi.org/ 10.1175/JAS-D-13-0305.1.

— , P. R. Field, R. M. Rasmussen, and W. D. Hall, 2008: Explicit forecasts of winter precipitation using an improved bulk microphysics scheme. Part II: Implementation of a new snow parameterization. Mon. Wea. Rev., 136, 5095-5115, https:// doi.org/10.1175/2008MWR2387.1.

Thompson, R. L., R. Edwards, J. A. Hart, K. L. Elmore, and P. Markowski, 2003: Close proximity soundings within supercell environments obtained from the Rapid Update Cycle. Wea. Forecasting, 18, 1243-1261, https://doi.org/10.1175/15200434(2003)018<1243:CPSWSE > 2.0.CO;2.

Thompson, W. T., and S. D. Burk, 1993: Postfrontal boundarylayer modification over the western Gulf of Mexico during GUFMEX. J. Appl. Meteor., 32, 1521-1537, https://doi.org/ 10.1175/1520-0450(1993)032<1521:PBLMOT>2.0.CO;2.

Trapp, R. J., and K. A. Hoogewind, 2016: The realization of extreme tornadic storm events under future anthropogenic climate change. J. Climate, 29, 5251-5265, https://doi.org/10.1175/ JCLI-D-15-0623.1.

, G. J. Stumpf, and K. L. Manross, 2005: A reassessment of the percentage of tornadic mesocyclones. Wea. Forecasting, 20, 680-687, https://doi.org/10.1175/WAF864.1.

, E. D. Robinson, M. E. Baldwin, N. S. Diffenbaugh, and B. R. Schwedler, 2011: Regional climate of hazardous convective weather through high-resolution dynamical downscaling. Climate Dyn., 37, 677-688, https://doi.org/10.1007/s00382-010-0826-y.
Trenberth, K. E., 1998: Atmospheric moisture residence times and cycling: Implications for rainfall rates and climate change. Climatic Change, 39, 667-694, https://doi.org/10.1023/ A:1005319109110.

_ J. T. Fasullo, and T. G. Shepherd, 2015: Attribution of climate extreme events. Nat. Climate Change, 5, 725-730, https:// doi.org/10.1038/nclimate2657.

Vescio, M., and R. Thompson, 1998: Some meteorological conditions associated with isolated F3-F5 tornadoes in the cool season. Preprints, 19th Conf. on Severe Local Storms, Minneapolis, MN, Amer. Meteor. Soc., 2-4.

von Storch, H., H. Langenberg, and F. Feser, 2000: A spectral nudging technique for dynamical downscaling purposes. Mon. Wea. Rev., 128, 3664-3673, https://doi.org/10.1175/ 1520-0493(2000)128<3664:ASNTFD>2.0.CO;2.

Vukovich, F. M., 2007: Climatology of ocean features in the Gulf of Mexico using satellite remote sensing data.J. Phys. Oceanogr., 37, 689-707, https://doi.org/10.1175/JPO2989.1.

Warner, M. S., 2018: Introduction to PySPLIT: A Python toolkit for NOAA ARL's HYSPLIT model. Comput. Sci. Eng., 20, 47-62, https://doi.org/10.1109/MCSE.2017.3301549.

Weisman, M. L., C. Davis, W. Wang, K. W. Manning, and J. B. Klemp, 2008: Experiences with 0-36-h explicit convective forecasts with the WRF-ARW Model. Wea. Forecasting, 23, 407-437, https://doi.org/10.1175/2007WAF2007005.1.

Weiss, S. J., 1992: Some aspects of forecasting severe thunderstorms during cool-season return-flow episodes. J. Appl. Meteor., 31, 964-982, https://doi.org/10.1175/1520-0450(1992) $031<0964$ :SAOFST $>2.0 . \mathrm{CO} ; 2$. 